2. To: (Receiving Organization)

Distribution

5. Proj./Prog./Dept./Div.:

Interim Stabilization

8. Originator Renarks:

Acceptance Test Plan for 500 CFM Portable Exhauster P0R-006, Skid D.

11. Receiver Remarks:
3. From: (Originating Organization)

FDNW TWRS Engineering

Services

6. Design Authority/ Design Agent/Cog. Engr.:

J. R. Kriskovich
11A. Design Basel ine Document? [X] Yes [] No

.

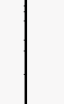

4. Related EDT No.:

$$
N / A
$$

7. Purchase Order No.:

$$
\mathrm{N} / \mathrm{A}
$$

9. Equip./Component No.: POR-006, Skid D

10. System/Bldg./Facility:

$$
N / A
$$

12. Major Assm. Dwg. No.:

13. Permit/Permit Application No.: $\mathrm{N} / \mathrm{A}$

14. Required Response Date:

$$
N / A
$$

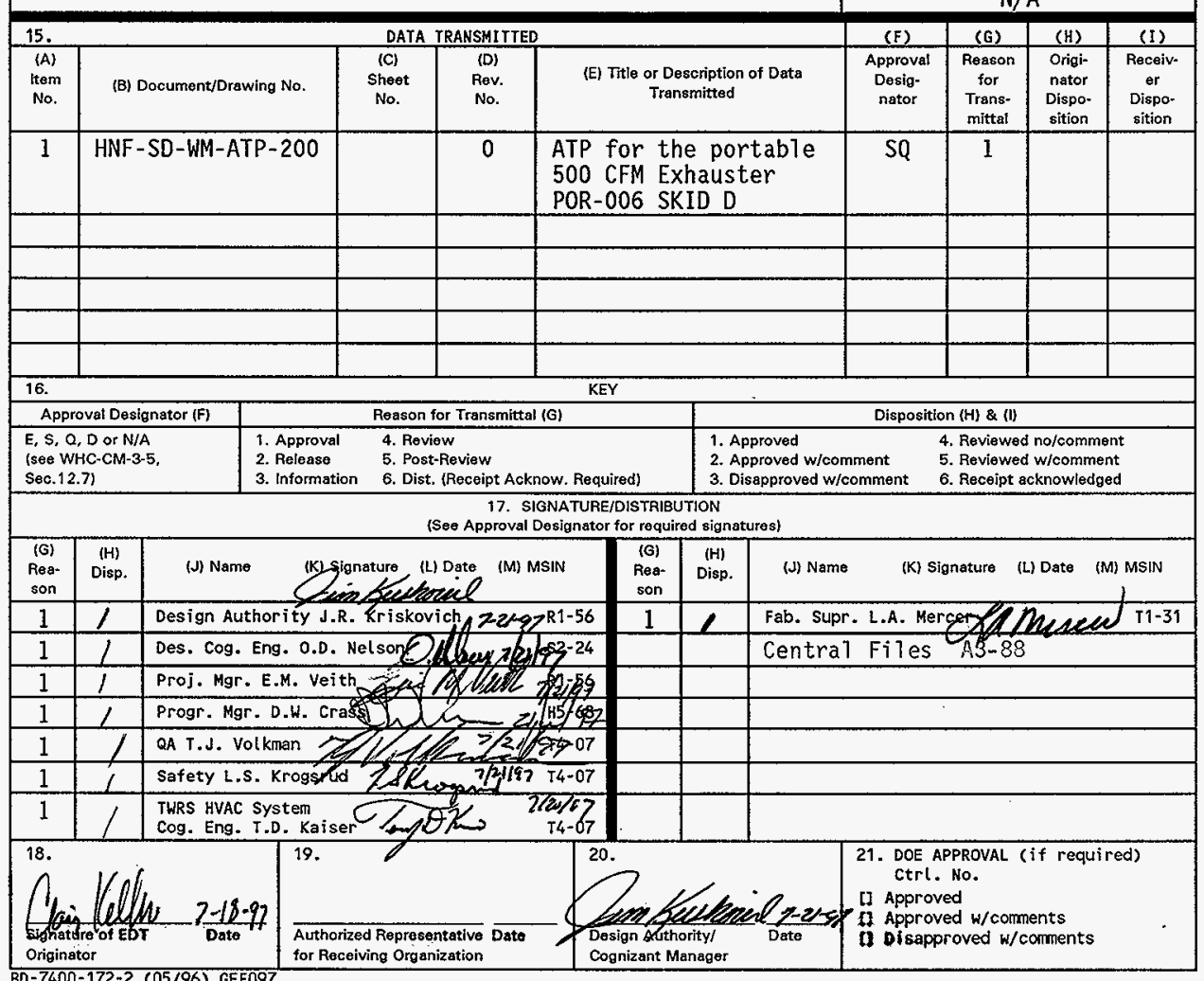


HNF-SD-WM-ATP-200, Rev. 0

\title{
ATP FOR THE PORTABLE 500 CFM EXHAUSTER POR-006 SKID D
}

\author{
Craig M. Keller
}

Fluor-Daniel Northwest, Richland, WA 99352

U.S. Department of Energy Contract DE-AC06-96RL13200

$\begin{array}{lll}\text { EDT/ECN: } & 161455 & \text { UC: } 2030 \\ \text { Org Code: } & 04 E 00 & \text { Charge Code: C13697 } \\ \text { B\&R Code: } & \text { EW3120072 } & \text { Total Pages: } 96\end{array}$

Key Words: Portable Exhauster, Saltwell Pumping, Waste Tank Ventilation, Flammable Gas Mitigation

Abstract: This Acceptance Test Plan is for a 500 CFM Portable Exhauster POR-006 to be used for saltwell pumping. The Portable Exhauster system will be utilized to eliminate potential flammable gases that may exist within the dome space of the tank. This Acceptance PIan will test and verify that the exhauster meets the specified design criteria, safety requirements, operations requirements, and will provide a record of the functional test results.

TRADEMARK DISCLAIMER. Reference herein to any specific comercial product, process, or service by trade name, trademark, manufacturer, or otherwise, does not necessarily constitute or imply its endorsement, recomendation, or favoring by the United States Government or any agency thereof or its contractors or subcontractors.

Printed in the United States of America. To obtain copies of this document, contact: Document Control Services, P.0. Box 950, Mailstop H6-08, Richland WA 99352, Phone (509) 372-2420;

Fax (509) 376-4989.
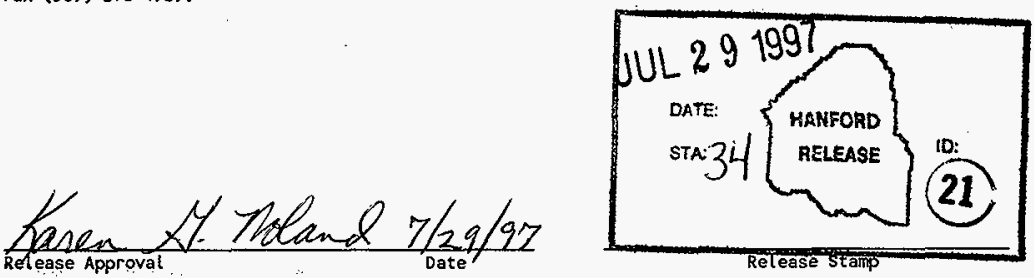

Approved for Public Release 


\section{TANK FARM}

ACCEPTANCE TEST PROCEDURE

\section{SYSTEM}

INTERIM STABILIZATION

ATP FOR THE PORTABLE 500 CFM EXHAUSTER, POR-006, SKID D

\section{CONTINUOUS USE}

\begin{tabular}{|c|c|c|c|}
\hline 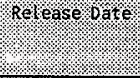 & 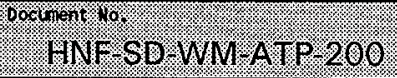 & 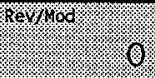 & 1. \\
\hline
\end{tabular}




\section{TEST EXECUTION SHEET}

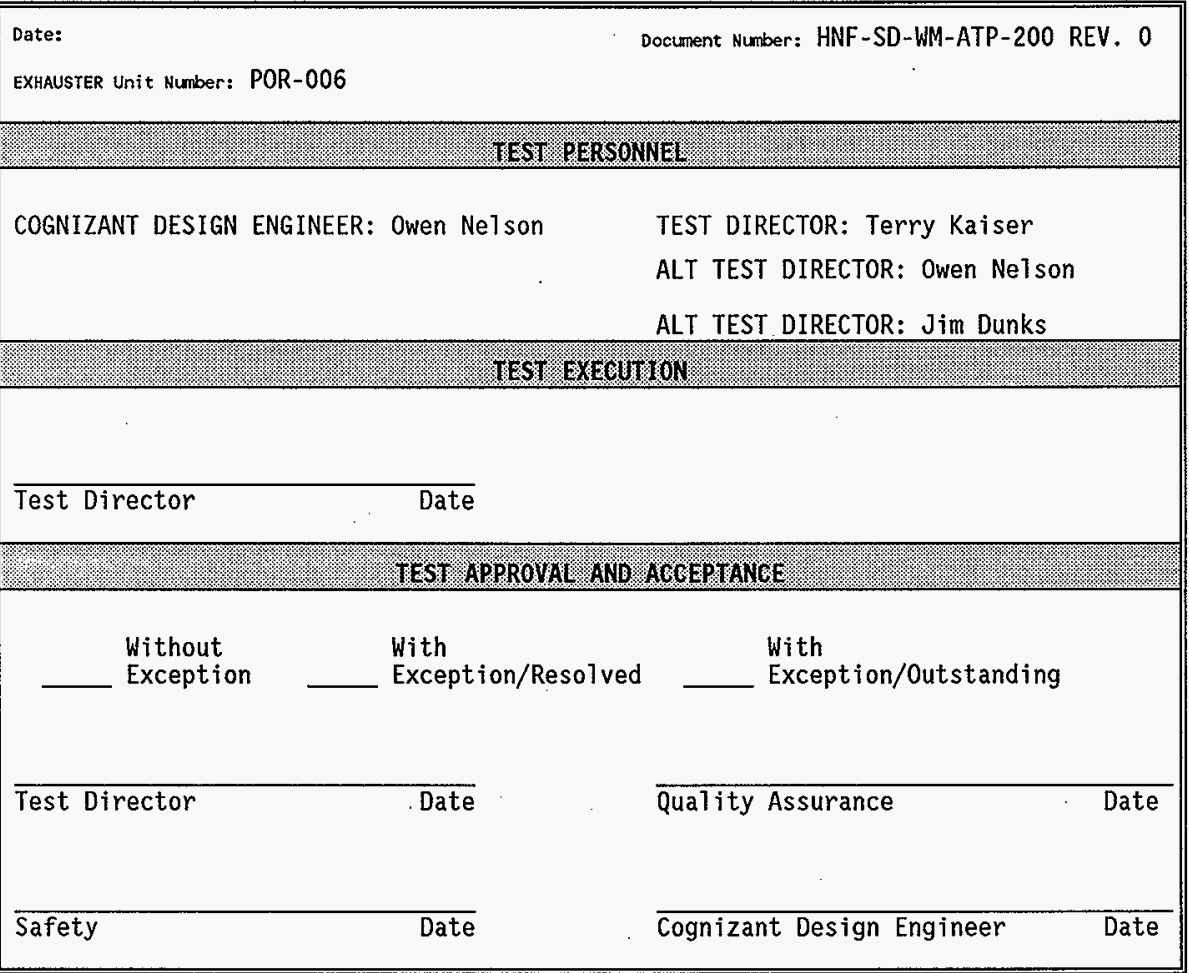




\section{TABLE OF CONTENTS}

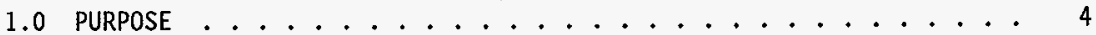

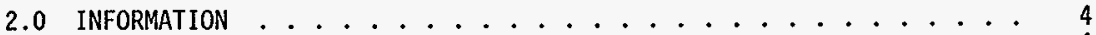

2.1 SCOPE . . . . . . . . . . . . . 4

2.2 TERMS AND DEFINITIONS .............. 5

2.3 RESPONSIBILITIES ................ 6

2.4 REFERENCES ................... . . . 8

2.5 SAFETY . . . . . . . . . . . . . . . 9

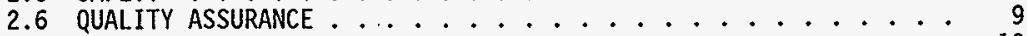

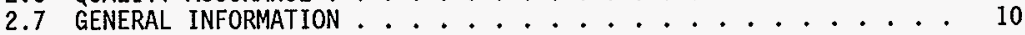

3.0 RECORDS ............................ 11

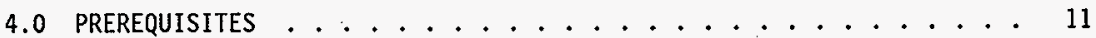

5.0 PROCEDURE . . . . . . . . . . . . . . . . 14

5.1 POWER SYSTEM CHECK .................... 14

5.2 CONDENSATE DRAIN TEST . . . . . . . . . . . 29

5.3 PRESSURE DECAY TEST . . . . . . . . . . . . 32

5.4 EXHAUSTER FAN CHECK ................ 38

5.5 HEAT TRACE CHECK ................ 43

5.6 FILTER \#1 DP INTERLOCK/ALARM CHECK ........... 45

5.7 FILTER \#2 DP INTERLOCK/ALARM CHECK ........... 52

5.8 FILTER \#1 \& \#2 DP INTERLOCK/ALARM CHECK .......... 59

5.9 PREFILTER DP INTERLOCK/ALARM CHECK .......... 66

5.10 STACK FLOW INTERLOCK/ALARM CHECK $\ldots \ldots 69$

5.11 SEAL POT INTERLOCK/ALARM CHECK $\ldots \ldots \ldots$

5.12 GLYCOL INTERLOCK/ALARM CHECK $\ldots \ldots \ldots$

5.13 GLYCOL SYSTEM LEAK CHECK ............... 83

5.14 THERMOCOUPLE INTERLOCK/ALARM CHECK $\ldots \ldots 6$

5.15 GLYCOL HEATER TEST . . . . . . . . . . . . . 89

DATA SHEET 1 - LEAKAGE RATE CALCULATION . . . . . . . . . 92

DATA SHEET 2 - LEAKage RATE CALCUlation . . . . . . . . . 93

ATP EXCEPTION LOG . . . . . . . . . . . . . . . . . . 94

ATP EXCEPTION RECORD ............................ 95

F.




\subsection{PURPOSE}

1.1 The purpose of this Acceptance Test Procedure is to test and verify that the portable 500 CFM Exhauster meets the specified Design Criteria, Safety requirements, Engineering requirements, and to assure adequacy of

fabrication. It will al so provide a record of the functional test results.

1.2 There is a concern that flammable gases may exceed the Lower Flammability Limit during interim stabilization of identified waste storage tanks. The Portable Exhauster System will be utilized to reduce potential flammable gases that exist within the dome vapor space of the tank.

\subsection{INFORMATION}

\subsection{SCOPE}

The systems/functions that will be tested are the following:

\subsubsection{CONDENSATE DRAIN TEST}

This check will verify that the condensate drain lines in the filter train are free of obstruction permitting liquids to drain to the seal pot.

\subsubsection{POWER SYSTEM CHECK}

This check will verify that there is power to the Exhauster systems.

\subsubsection{PRESSURE DECAY TEST}

This will check integrity of the Exhauster train assembly air boundary, including the Sea] Pot.

\subsubsection{EXHAUSTER FAN CHECK}

This check will verify that the Exhauster Fan rotates in the correct direction.

\subsubsection{HEAT TRACE CHECK}

This check will verify that the Heat Trace functions properly.

\subsubsection{FILTER \# 1 INTERLOCK/ALARM CHECK}

This check will verify that 1st HEPA filter interlocks perform as required to specific alarm conditions for rupture or plugging of the HEPA. 


\section{TANK FARM ACGEPTANCE TEST PROCEDURE}

2.1 SCOPE (continued)

\subsubsection{FILTER \# 2 INTERLOCK/ALARM CHECK}

This check will verify that 2nd HEPA filter interlocks perform as required to specific alarm conditions for rupture or plugging of the HEPA.

\subsubsection{FILTER \#1 \& \#2 INTERLOCK/ALARM CHECK}

This check will verify that 1st \& 2nd HEPA filter interlocks perform as required to specific alarm conditions for rupture or plugging of the HEPA.

\subsubsection{PRE-FILTER ALARM CHECK}

This check will verify that Pre-filter alarm perform as required to specific alarm conditions if the pre-filter starts plugging.

2.1.10 STACK FLOW INTERLOCK/ALARM CHECK

This check will verify that Stack Flow interlocks perform as required to specific alarm conditions to shutdown the exhauster.

\subsubsection{SEAL POT INTERLOCK/ALARM CHECK}

This check will verify that Seal Pot interlocks perform as required to specific alarm conditions to shutdown the exhauster.

\section{1,12 GLYCOL SYSTEM LEAK TEST}

This will check integrity of the Glycol System assembly.

\subsubsection{THERMOCOUPLE INTERLOCK/ALARM CHECK}

This check wi7l verify that 1st HEPA filter interlocks perform as required to specific alarm conditions to shutdown the glycol heating system.

\subsubsection{GLYCOL HEATER CHECK}

This check will verify that the Heater and Glycol Circulation Pump function properly.

\subsection{TERMS AND DEFINITIONS}
2.2.1 ATP - Acceptance Test Procedure
2.2.2 DMM - Digital Multimeter 


\subsection{TERMS AND DEFINITIONS (Continued)}
2.2.3 DPT - Differential Pressure Transmitter
2.2.4 DS - Disconnect Switch
2.2.5 HEPA - High Efficiency Particulate Air
2.2.6 MPZ - Mini Power Zone
2.2.7 MSDS - Material Safety Data Sheet
2.2.8 NO - Normally Open
2.2.9 SLC - Small Logic Controller
2.2.10 QC - Quality Control
2.2.11 IN W.C. - inches Water Column

\subsection{RESPONSIBILITIES}

2.3.1 The Maintenance craft personnel are responsible for the following:

- Schedule the test as required.

- Provide the test supplies found in step 4.1.

- Provide assistance during the test.

2.3.2 Design Cognizant Engineer is responsible for the following:

- Designate a Test Director.

- Coordinate testing with facility management.

- Ensure field testing and inspection has been completed.

- ScheduTe a pre-ATP meeting with test participants prior to start of testing.

- Sign Test Execution Sheet as cognizant engineer when the ATP is approved and accepted.

- Take necessary action to clear exceptions to the ATP.

- Sign Exception Sheet when exception has been resolved.

- Provide a distribution list for the approved and accepted ATP. 


\subsection{RESPONSIBILITIES (Continued)}

- Retain the working copy and a copy of the master in the field project files.

- Compile information and issue Acceptance Test Report.

2.3.3 Test Director is responsible for the following:

- Coordinate all acceptance testing.

- Notify all concerned parties when a change is made in the testing schedule.

- Conduct pre-job safety meeting.

- Conduct pre-job system walkdown.

- Confirm that field testing and inspection of the system or portion of the system to be tested has been completed.

- Obtain from the Design Cognizant Engineer, any information or changes necessary to clear or resolve objections.

- Stop any test which may cause damage to the system until the test procedure has been revised.

- Observe tests, record test data and maintain test log.

- Evaluate recorded data, discrepancies, and exceptions.

- Approve and record authorized field changes to the ATP using the red line method.

- Sign and date every procedure section on the working copy as it is completed.

- Sign Test Execution Sheet when ATP has been performed.

- Sign Test Exception Sheet when retest has been executed and accepted.

- Record exceptions and test steps that are not performed on the ATP EXCEPTION RECORD. Add additional ATP EXCEPTION RECORD sheets as needed.

- Transfer the final test results with Quality Control's signatures and dates for each applicable section to the master in ink or type.

2.3.4 Quality Assurance is responsible for the following: 


\subsection{RESPONSIBILITIES (Continued)}

- Approval of testing by signing Test Execution sheet.

- Approval of Acceptance Test Report.

2.3.5 Quality Control is responsible for the following:

- Verifying/Witnessing results of testing to established criteria as identified in the Test Procedure.

- Signing and verifying completion of sections 5.3 Pressure Decay Test and 5.13 Glycol System Leak Check.

- Signing Test Data Sheets.

- Approval of test exceptions by signing ATP Exception Records

2.3.6 Safety is responsible for the following:

- Signing Test Execution sheet.

\subsection{REFERENCES}

2.4.1 The following documents were used to write or are referenced in this procedure:

- HNF-PRO-079, PRE-JOB SAFETY PLANNING and HNF-PR0-088, ELECTRICAL WORK SAFETY.

- WHC-CM-6-1 EP 4.2., STANDARD ENGINEERING PRACTICE, "TESTING REQUIREMENTS"

- WHC-IP-1026 APP M, ENGINEERING PRACTICE GUIDELINES "ACCEPTANCE TEST PROCEDURES AND REPORTS"

- H-14-100867, 500 CFM PORTABLE EXHAUSTER'S B, C, \&D (Mechanica1 drawings)

- H-14-100868, EXHAUSTER B, C, \&D CONNECTION DIAGRAM (ElectricaT drawings)

- H-14-100869, ELECTRICAL EXHAUSTER B, C, \& D SKID ELEVATIONS AND PLAN drawings

- H-14-100807, ELECTRICAL EXHAUSTER B, C, \& D SKID DETAILS drawings

- H-14-100916, ELECTRICAL SAMPLE CABINET, (GEMS drawings) 


\subsection{REFERENCES (Continued)}

- H-14-020160, EXHAUSTER PIPING \& INSTRUMENT DIAGRAM

- ASME, 1989a, Nuclear Power Plant Air-Cleaning Units and Components, ASME N509-1989, American Society of Mechanical Engineers (ASME), New York.

- ASME, 1989b, Testing of Nuclear Air Treatment Systems, ASME N510-1989, ASME, New York.

- VENDOR INFORMATION

\subsection{SAFETY}

Warning - Energized circuits and leads are contained inside the cabinets. Observe appropriate electrical precautions. Comply with HNFPRO-088, ELECTRICAL WORK SAFETY.

Caution - Do not apply Megger voltage to the Variable Frequency Drive VTP-VFD-001. Damage to the drive may result.

2.5.1 The following administrative procedures control work performed in this procedure:

- $277 \mathrm{~W}$ Boiler Shop Emergency Preparedness Plan

- Industrial Hygiene Manual, WHC-CM-4-40

- Safety Manual, WHC-CM-1-10

\subsection{QUALITY ASSURANCE}

A Quality Assurance Engineer will be provided by Lockheed Martin Hanford Company. Quality Assurance wi11 approve the Acceptance Test P1an document, Test Execution sheet, and the Acceptance Test Report.

A Quality Control representative will provide witnessing and verification of testing activities as defined in Section 2.3.5 of this document. It is anticipated that Dyncorp Fabrication Services will provide Quality Control personnel to support testing activities. Substitute Quality Control personnel may be used at the discretion of the Test Director and the Quality Assurance Engineer. 


\subsection{GENERAL INFORMATION}

2.7.1 Complete each procedure step in the given order, unless otherwise noted, or as directed by the Test Director.

2.7.2 All entries recorded in this procedure shall be made in black ink except for those noted using the redline method.

2.7.3 Editorial changes required to this ATP may be made per the red line method by the Test Director as long as they do not impact operational facility safety function or performance, and will not compromise or influence the test data. Any changes affecting the above stated criteria sha11 be made in accordance with WHC-CM-6-1, Standard Engineering Practices, EP-2.2, Engineering Document Change Control Requirements.

2.7.4 Any non-conformance of the instrumentation, unexpected results, or exceptions during testing shall be sequentially numbered and recorded in the ATP EXCEPTION LOG. Thus, case-by-case resolution, recording, approvat, and distribution of each exception will be achieved.

2.7.5 Do not perform any part of this procedure on faulty equipment. If faulty equipment is discovered, STOP the execution of this procedure and resolve the problem (i.e. repair equipment or write up faut ty equipment as an exception and continue).

2.7.6 At the completion of daily ATP testing, or if testing is suspended for any reason, ensure that the 500 CFM Portable Exhauster is shutdown and in a safe de-energized state.

2.7.7 The intent of this ATP is to provide a method for documenting the condition and capabilities of the as-built Exhauster unit. The attached ATP Exception Log and Exception Record provides the means of documenting Acceptance Testing resuits and equipment conditions. Additional sheets are to be used as necessary to delineate the progress of the ATP.

2.7.8 The performance of this test may take several days. At the end of each day the power to all circuits must be turned off. The Test Director will ensure proper power is restored as needed.

2.7.9 There are no special training requirements beyond Hanford General Employee Training for testing personnel.

2.7.10 During operation of the atarm interlock checks the message view may display "Fan Shutdown" before the initial alarm. This is NOT an exception and may be cleared any time it is displayed. 


\subsection{RECORDS}

3.1 The completed working copy of this procedure and a.11 exception logs and exception records generated by this procedure will be kept as permanent records.

\subsection{PREREQUISITES}

4.1 The following supplies will be needed to perform this procedure:

- Yokogawa hand held transmitter configurer BT-200.

- Digital Multi-Meter: Portable, $0-600$ volts $A C, \pm 2 \%$ accuracy.

- Propylene Glycol (An amount that will fill system to $60 \%$ of volume with a 50/50 mixture of propylene glycol and deionized water).

- Pressure measurement device, accurate to $\pm 0.1 \mathrm{in}$. wg, approximate range of 0 to $12 \mathrm{in.} \mathrm{wg.}$

Calibration No. Expiration Date

- Pressure measurement device, suitable for water or water/glycol mixture, range from 0 to minimum 15 and maximum 40 psig with maximum 1 psi graduation.

Calibration No. Expiration Date

- Pressure source: water or water/glycol mixture, 0 - 10 psig

- Barometer, accurate to $\pm 0.01 \mathrm{in}$. $\mathrm{Hg}$, or use Hanford weather station data (373-2716)

Reading:

- Compressed air source (or blower), pressure reducer (or damper), isolation valve, and safety relief mechanism

- Vacuum source (Capable of producing -12.0 IN W.C) and isolation valve.

- Vibration Instrument, SKF CMVAIO (or as specified by Project Engineer) Calibration No. Expiration Date

- Desktop/Laptop computer to interface with the Exhauster SLC Logic program.

- $480 \mathrm{~V}, 3$ phase power source. 


\section{TANK FARM ACCEPTANCE TEST PROCEDURE}

\subsection{PREREQUISITES (Continued)}

- $1000 \mathrm{~V}$ and $500 \mathrm{~V}$ megohmeter.

- Clamp on $A C$ ammeter for indication only

- Portable Calibration System (C-Box) Model 401-18-20 by DrexelBrook.

4.2 The following documents are required to perform this procedure:

- Engineering drawings and appropriate vendor information listed in section 2.4 .

- Propylene Glycol MSDS (\#01552)

4.3 The following conditions must be met before this test may commence:

4.3.1 HOLD a pre-job safety meeting has been held in accordance with IS\#, PRE-JOB SAFETY PLANNING, ICF KH ENVIRONMENTAL, SAFETY, AND HEALTH PROGRAM MANUAL.

4.3.2 VERIFY that the Exhauster is ready for testing by walking down the test area to identify and clear all hazardous conditions.

4.3.3 ENSURE a17 Exhauster valves are closed.

\begin{tabular}{|c|c|c|c|}
\hline Wurevininar & Mosed & Yaver number & (6) \\
\hline 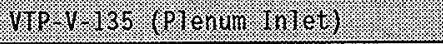 & & 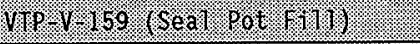 & \\
\hline 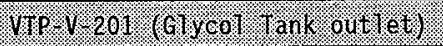 & & 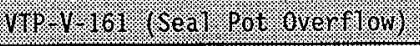 & \\
\hline 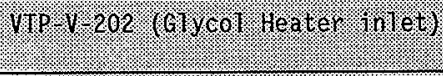 & & 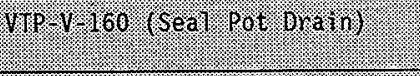 & \\
\hline 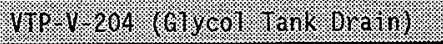 & & 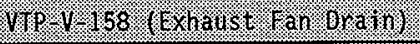 & \\
\hline W & & 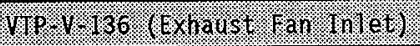 & \\
\hline
\end{tabular}

4.3.4 ENSURE/CLOSE a11 Exhauster DPT valves are closed, except for the stack pitot valves. 


\section{TANK FARIV ACEEPTANOE IEST PROGEDURE:}

\subsection{PREREQUISITES (Continued)}

\begin{tabular}{|c|c|c|c|c|c|c|}
\hline BPf & Hath & \%oseg & (x) & orsea & Ware & cosedry \\
\hline 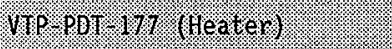 & 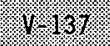 & & $1=1.88$ & & $1=139$ & \\
\hline 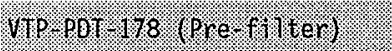 & 1.640 & & 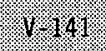 & & 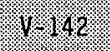 & \\
\hline MP & 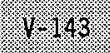 & & x. & & $\sqrt{2}+45$ & \\
\hline 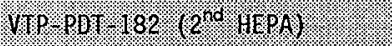 & 17.149 & & 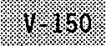 & & 1. & \\
\hline 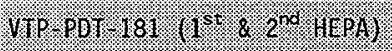 & v. 46 & & 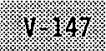 & & $\sqrt{1}$ & \\
\hline
\end{tabular}

4.3.5 VERIFY the Exhauster has been electrically grounded.

4.3.6 Test Director SHALL VERIFY that section 4.0 is COMPLETE by SIGNING below.

Test Director Signature

$\overline{\text { Date }}$ 


\subsection{PROCEDURE}

\subsection{POWER SYSTEM CHECK}

5.1.1 VERIFY Main 480V Disconnect Switch VTP-DS-101 is in the OFF position.

5.1.3 VERIFY Exhauster Fan VTP-EF-001 Motor 480V Disconnect Switch VTP-DS-102 is in the OFF position.

5.1.2 VERIFY G]ycol Heater 480V Disconnect Switch VTP-DS-201 is in the OFF position.

5.1.3 VERIFY that Mini Power Zone 480V "primary" Circuit Breaker VTPBRK-101 (located at Mini Power Zone Cabinet VTP-PNL-101) is OFF.

5.1.4 VERIFY that Mini Power Zone 120V "secondary" Circuit Breaker VTPBRK-102 (Tocated at MPZ Cabinet) is OFF. 


\subsection{POWER SYSTEM CHECK (Continued)}

5.1.5 VERIFY the following $120 \mathrm{~V}$ circuit breakers (located at MPZ Cabinet) are OFF:

- Circuit Breaker \# 1 (Enclosure Heaters \& Fans, Action Paks, Sample Enclosure Heater \& Fan)

- Circuit Breaker \#2 (Future Flammable Gas Monitor) SPARE

- Circuit Breaker \# 3 (SLC Power \& Message Views, Sampler Flow Control Power Supply)

- Circuit Breaker \#4 (Heat Trace/Flammable Gas Monitor Cab Heat Trace/Sampler Heat Trace)

- Circuit Breaker \#5 (Convenience Receptac7e)

- Circuit Breaker \#6 (SLC Control Circuit, ModuTe 8/VFD-001)

- Circuit Breaker \# 7 (SLC Control Circuit, (MOD 9))

- Circuit Breaker \#8 (Air Monitor Vac Pumps / Cabinet Heater \& Fan) SPARE

5.1.6 VERIFY Fan/Off/Enable Control Selector Switch VTP-HS-103 (located on door of Exhauster control Cabinet VTP-CP-105) is in the OFF position.

5.1.7 VERIFY G1ycol Pump Control Switch VTP-HS-102 (located on door of ControT Cabinet VTP-CP-105) is in the OFF position. 


\section{TANK FARM ACCEPTANCE TEST PROCEDURE}

\subsection{POWER SYSTEM CHECK (Continued)}

5.1.8 VERIFY Seal Pot Pump Control Selector Switch VTP-HS-101 (located on door of Exhauster Control Cabinet VTP-CP.105) is in the AUTO position.

5.1.9 VERIFY CAB HEAT/COOL Selector Switch VTP-HS-105 (Located on door of Control Cabinet VTP-CP-105) is in OFF position.

5.1.10 VERIFY CAB HEAT/COOL Selector Switch VTP-HS-104 (Located on door of Heat Trace Cabinet VTP-ENCL-104) is in OFF position.

5.1.11 INSTALL Personat Locking Device on Main 480V Disconnect Switch VTP-DS-101.

5.1.12 DISCONNECT Exhauster fan motor circuit from the Variable Frequency Drive (VTP-VFD-001) terminals T1, T2 and T3.

\section{CAUTION}

Do not apply Megger voltage to the Variable Frequency Drive VTP-VFD-001. Damage to the drive may result.

5.1.13 USING A 1000V Megger, megger between T1, T2 and T3 leads to ground to ENSURE there is NOT a short between the exhauster fan motor windings and ground.

READING: Megohm

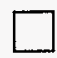

5.1.14 RECONNECT Exhauster fan motor circuit to the Variable Frequency Drive (VTP-VFD-001) terminals $\mathrm{Tl}, \mathrm{T} 2$ and $\mathrm{T} 3$. 


\subsection{POWER SYSTEM CHECK (Continued)}

5.1.15 USING a 1000V Megger, megger test at the Heater Contactor VTP-CON206 load side (located at Heat Trace Cabinet VTP-ENCL-104), ENSURE there is NOT a short between Heater circuits and the Heater housing.

READING: Megohm

5.1.16 DISCONNECT neutrat lead of the heat trace.

5.1.17 USING a 500V Megger, VERIFY that Heat Trace heating leads insulation resistance to ground is greater than 100 Megohms.

READING $(H)$ : Megohm

READING (N): Megohm

5.1.18 USING a DMM, VERIFY that Heat Trace heating leads resistance is less then 1000 ohms between leads.

5.1.19 RE-CONNECT neutral lead of the heat trace.

5.1.20 CONNECT the Exhauster to a $480 \mathrm{~V} 3$ phase power source:

5.1.21 REMOVE Personal Locking Device on Main 480V Disconnect Switch VTPDS-101.

5.1.22 POSITION Main 480V Disconnect Switch VTP-DS-101 to ON position. 


\subsection{POWER SYSTEM CHECK (Continued)}

\section{WARNING}

Energized circuits and leads are contained inside the cabinet. Observe appropriate electrical precautions. Comply with HNF-PRO-088, ELECTRICAL WORK SAFETY.

5.1.23 CLOSE Mini Power Zone 480V "primary" Circuit Breaker VTP-BRK-101 (located at Mini Power Zone Cabinet VTP-PNL-101).

5.1.24 CLOSE Mini Power Zone 120V "secondary" Circuit Breaker VTP-BRK-102 (located at MPZ Cabinet). 


\subsection{POWER SYSTEM CHECK (Continued)}

5.1.25 POSITION the following $120 \mathrm{~V}$ circuit breakers (located at MPZ Cabinet) to ON:

- Circuit Breaker \# I (Enclosure Heaters \& Fans, Action Paks, Sample Enclosure Heater \& Fan)

- Circuit Breaker \# 2 (Future Flammable Gas Monitor) SPARE

- Circuit Breaker \# 3 (SLC Power \& Message Views, Sampler Flow Control Power Supply)

- Circuit Breaker \#4 (Heat Trace/FTammable Gas Monitor Cab Heat Trace/Sampler Heat Trace)

- Circuit Breaker \# 5 (Convenience Receptacle)

- Circuit Breaker \#(6 SLC Control Circuit, Module 8/VFD-001)

- Circuit Breaker \#7 (SLC Control Circuit, (MOD 9))

- Circuit Breaker \#8 (Air Monitor Vac Pumps / Cabinet Heater \& Fan) SPARE

5.1.26 PRESS red EMERGENCY STOP button VTP-PB-103 (1 ocated on door of Main 480V Disconnect Switch VTP-DS-101).

5.1.27 VERIFY the Main 480V Disconnect Switch Circuit Breaker VTP-DS-101 has tripped. 


\subsection{POWER SYSTEM CHECK (Continued)}

5.1.28 RESET the Main 480V Disconnect Switch Circuit Breaker VTP-DS-101 to ON position.

5.1.29 VERIFY Green FAN OFF 1ight (1ocated on door of exhauster Control Cabinet) is ILLUMINATED.

5.1.30 VERIFY Red FAN RUNNING 1ight (located on door of exhauster Control Cabinet) is NOT ILLUMINATED.

5.1.3I VERIFY Glycol Heater is OFF by OBSERVING that the Glycol Heater Contactor VTP-CON-206 contactor (located in Heat Trace Cabinet VTP-ENCL-104) is OFF.

5.1.32 VERIFY the Glycol Circulation Pump is OFF by LISTENING to and/or FEELING the pump.

5.1.33 VERIFY the "HEAT TRACE ON" Indicating Light (located on door of Heat Trace Cabinet VTP-ENCL-104) is NOT ILLUMINATED.

5.1.34 VERIFY Exhauster Control Cabinet Heater VTP-HTR-105 is OFF.

5.1.35 VERIFY Exhauster Control Cabinet Fan VTP-F-105 is OFF.

5.1.36 VERIFY Cabinet Heater VTP-HTR-106 in Intrinsic Barrier Cabinet is OFF.

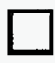

5.1.37 VERIFY Cabinet Fan VTP-F-106 in Intrinsic Barrier Cabinet is OFF.

5.1.38 VERIFY Cabinet Heater VTP-HTR-104 in Heat Trace Cabinet is OFF. 


\subsection{POWER SYSTEM CHECK (Continued)}

5.1.39 VERIFY Cabinet Fan VTP-F-104 in Heat Trace Cabinet is OFF.

5.1.40 VERIFY ATarm Cabinet Heater VTP-HTR-107 is OFF.

5.1.41 VERIFY A7arm Cabinet Fan VTP-F-107 is OFF.

5.1.42 POSITION Main 480V Disconnect Switch Circuit Breaker VTP-DS-101 to OFF position.

5.1.43 REMOVE electrical pane1 cover at MPZ cabinet.

5.1.44 POSITION Main 480V Disconnect Switch Circuit Breaker VTP-DS-101 to ON position.

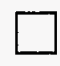




\subsection{POWER SYSTEM CHECK (Continued)}

\section{WARNING}

Energized circuits and leads are contained inside the cabinet.

Observe appropriate electrical precautions. Comply with HNF-PRO-088, ELECTRICAL WORK SAFETY.

5.1.45 USING a DMM, VERIFY $120 \mathrm{~V}$ at the following circuit breakers (located at MPZ cabinet):

- Circuit Breaker \# I (Enclosure Heaters \& Fans, Action Paks, Sample Enclosure Heater \& Fan)

- Circuit Breaker \#2 (Future Flammable Gas Monitor) SPARE

- Circuit Breaker \# 3 (SLC Power \& Message Views, Sampler Flow Control Power Supply)

- Circuit Breaker \# 4 (Heat Trace/Flammable Gas Monitor Cab Heat Trace/Sampler Heat Trace)

- Circuit Breaker \#5 (Convenience Receptac7e)

- Circuit Breaker \# 6 SLC Control Circuit, Module 8/VFD-001

- Circuit Breaker \#7 (SLC Control Circuit, (MOD 9))

- Circuit Breaker \#8 (Air Monitor Vac Pumps / Cabinet Heater \& Fan) SPARE

5.1.46 PRESS Ground Fau7t Circuit Interrupter button at Circuit Breaker \#5 (located at MPZ Cabinet). 


\section{TANK FARM ACCEPTANCE TEST PROG EUURE}

\subsection{POWER SYSTEM CHECK (Continued)}

5.1.47 VERIFY circuit breaker \#5 has tripped.

5.1.48 RESET circuit Breaker \#5.

5.1.49 PRESS the button of Ground Fault Protection for Equipment (1ocated at MPZ Cabinet Circuit Breaker \#4).

5.1.50 VERIFY circuit Breaker \#4 (located at MPZ Cabinet) has tripped.

5.1.51 RESET circuit Breaker \#4.

5.1.52 POSITION Main 480V Disconnect Switch Circuit Breaker VTP-DS-101 to OFF position.

5.1.53 RE-INSTALL electrical panel cover at MPZ cabinet.

5.1.54 POSITION Main 480V Disconnect Switch Circuit Breaker VTP-DS-101 to ON position.

NOTE: The following steps verify proper operation of the Cabinet Cooling Fans and Cabinet Heaters.

5.1.55 SET the Alarm Cabinet Heater VTP-HTR-107 thermostat temperature to above the ambient temperature.

5.1.56 SET the Control Cabinet Heater VTP-HTR-105 thermostat temperature to above the ambient temperature.

5.1.57 POSITION the Control Cabinet Selector switch "CAB HEAT/COOL Selector" VTP-HS-105 to "SUMMER". 


\subsection{POWER SYSTEM CHECK (Continued)}

5.1.58 VERIFY the following:

- Control Cabinet Cooling Fan VTP-F-105 is rotating.

- Control Cabinet Cooling Fan VTP-F-105 air flow is flowing from the outside to the inside of the cabinet.

- Alarm Cabinet Cooling Fan VTP-F-107 is rotating.

- Alarm Cabinet Cooling Fan VTP-F-107 air flow is flowing from the outside to the inside of the cabinet.

- Control Cabinet Heater VTP-HTR-105 is OFF.

- Alarm Cabinet heater VTP-HTR-107 is OFF.

5.1.59 POSITION the control cabinet selector switch "CAB HEAT/COOL" VTPHS-105 to "Winter".

5.1.60 VERIFY the following:

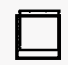

- Control Cabinet Cooling Fan VTP-F-105 is OFF.

- Alarm Cabinet Cooling Fan VTP-F-107 is OFF.

- Control Cabinet Heater VTP-HTR-105 is ON.

- Alarm Cabinet Heater VTP-HTR-107 is ON. 


\subsection{POWER SYSTEM CHECK (Continued)}

5.1.61 SET the Control Cabinet Heater VTP-HTR-105 thermostat temperature to below the ambient temperature.

5.1.62 VERIFY Control Cabinet Heater element VTP-HTR-105 is 0FF and Heater fan is ON.

5.1.63 SET the Alarm Cabinet Heater VTP-HTR-107 thermostat temperature to below the ambient temperature.

5.1.64 VERIFY Alarm Cabinet Heater element VTP-HTR-107 is OFF and Heater fan is ON.

5.1.65 POSITION the Control Cabinet Selector Switch "CAB HEAT/COOL" VTPHS-105 to OFF.

5.1.66 POSITION the Heat Trace Cabinet Selector switch "CAB HEAT/COOL Selector" VTP-HS-104 to "SUMMER".

5.1.67 VERIFY the following:

- Heat Trace Cabinet Cooling Fan VTP-F-104 is rotating.

- Heat Trace Cabinet Cooling Fan VTP-F-104 air flow is flowing from the outside to the inside of the cabinet.

- Intrinsic Barrier Cooling Fan VTP-F-106 is rotating.

- Heat Trace Cabinet Heater VTP-HTR-104 is OFF.

- Intrinsic Barrier Cabinet heater VTP-HTR-106 is OFF. 


\subsection{POWER SYSTEM CHECK (Continued)}

5.1.68 POSITION the Heat Trace cabinet selector switch "CAB HEAT/COOL" VTP-HS-104 to "Winter".

5.1.69 VERIFY the following:

- Heat Trace Cabinet Cooling Fan VTP-F-104 is OFF.

- Intrinsic Barrier Cabinet Cooling Fan VTP-F-106 is OFF.

- Heat Trace Cabinet Heater VTP-HTR-104 is ON.

- Intrinsic Barrier Cabinet Heater VTP-HTR-106 is ON.

5.1.70 SET the Heat Trace Cabinet Heater VTP-HTR-104 thermostat temperature to below the ambient temperature.

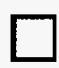




\section{TANK FARM ACOEPT ANCE TEST PROCEDURE}

\subsection{POWER SYSTEM CHECK (Continued)}

\section{WARNING}

Energized circuits and lead are contained inside the cabinet.

Observe Appropriate electrical precautions. Comply with HNF-PRO-

88, ELECTRICAL WORK SAFETY.

5.1.75 USING a DMM, VERIFY $120 \mathrm{~V}$ at the Mini Power Zone Cabinet (VTP-PNL101) Receptacle.

5.1.76 USING a DMM, VERIFY $120 \mathrm{~V}$ at the Alarm Cabinet (VTP-ENCL-107) Receptacle.

5.1.77 VERIFY the Wilkerson indicators are illuminated by visual inspection. Fill in the following table.

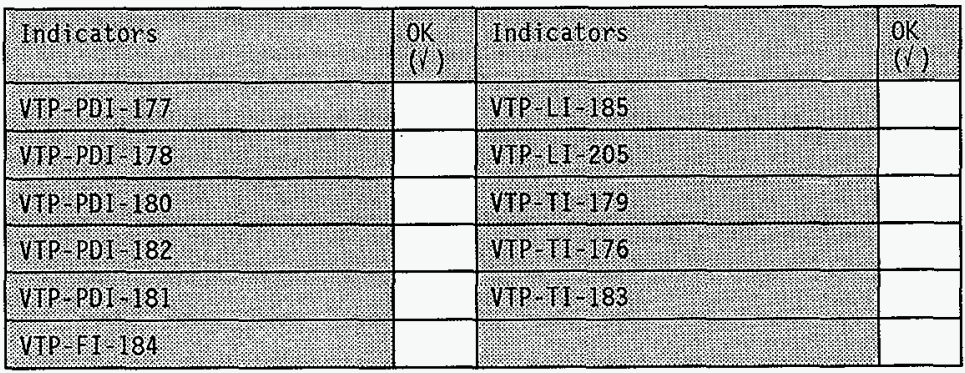

5.1.78 VERIFY the Green FAN OFF indicating 7ight (located on the door of the Exhauster Control Cabinet VTP-CP-105) is ILLUMINATED: 


\section{TANK FARM AOCEPTANCE TEST PROOEDURE}

\subsection{POWER SYSTEM CHECK (Continued)}

5.1.79 VERIFY the digital readouts on the following six DPTs.

\begin{tabular}{|c|c|c|c|}
\hline hransmitier : & $104:$ & Iransintiven: & \\
\hline 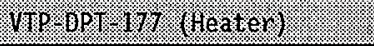 & & 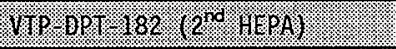 & \\
\hline 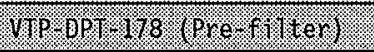 & & 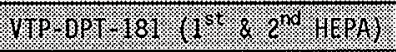 & \\
\hline 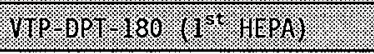 & & 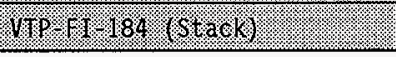 & \\
\hline
\end{tabular}

5.1.80 POSITION the following $120 \mathrm{~V}$ circuit breakers (located at MPZ Cabinet) to OFF.

- Circuit Breaker \#2 (Future Flammable Gas Monitor) SPARE

- Circuit Breaker \#8 (Air Monitor Vac Pumps / Cabinet Heater \& Fan)

5.1.81 Test Director SHALL VERIFY that section 5.2 is COMPLETE by SIGNING below.

$\overline{\text { Test Director Signature }}$

Date 


\subsection{CONDENSATE DRAIN TEST}

This section of the procedure will verify that the condensate drains are free of obstructions and capable of draining liquids to the seal pot. Depending on the system configuration, some of the condensate drains may not be accessible for testing.

5.2.1 REMOVE the $1^{\text {st }} \& 2^{\text {nd }}$ stage HEPA filter and Pre-filter access doors.

5.2.2 REMOVE blind flange from Seal Pot Drain Valve VTP-V-160.

5.2.3 OPEN Seal Pot Overflow Valve VTP-V-161.

5.2.4 OPEN SeaT Pot Drain Valve VTP-V-160 AND DRAIN any liquids.

5.2.5 POUR water into the Pre-Filter Condensate Drain until it exits the Seal Pot Drain Valve VTP-V-160, or until about 1 gallon of water has been added.

5.2.6 VERIFY the Pre-Filter Condensate Drain is functional by observing water exiting the seal pot drain.

5.2.7 POUR water into the First Test Section Condensate Drain unit it exits the Seal Pot Drain Valve VTP-V-160, or until about 1 gallon of water has been added.

5.2.8 VERIFY the First Test Section Condensate Drain is functional by observing water exiting the seal pot drain.

5.2.9 POUR water into the First Hepa Section Condensate Drain until it exits the Seal Pot Drain Valve VTP-V-160, or until about 1 gallon of water has been added.

\begin{tabular}{|c|c|c|c|}
\hline 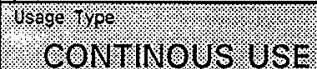 & 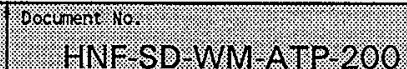 & 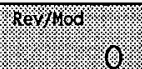 & Page $=0$ \\
\hline
\end{tabular}




\section{TANK FARIV ACGEPTANOE TEST PROCEDURE}

\subsection{CONDENSATE DRAIN TEST (Continued)}

5.2.10 VERIFY the First Hepa Section Condensate Drain is functional by observing water exiting the seal pot drain.

5.2.11 POUR water into the Second Test Section Condensate Drain until it exits the Seal Pot Drain Valve VTP-V-160, or until about 1 gallon of water has been added.

5.2.12 VERIFY the Second Test Section Condensate Drain is functional by observing water exiting the seal pot drain.

5.2.13 POUR water into the Second Hepa Section Condensate Drain until it exits the Seal Pot Drain Vaive VTP-V-160, or until about 1 galion of water has been added.

5.2.14 VERIFY the Second Hepa Section Condensate Drain is functional by observing water exiting the seal pot drain.

5.2.15 OPEN the Fan Condensate Drain Valve VTP-V-158.

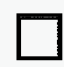
5.2.16 POUR water into the Fan Condensate Drain until it exits the Seal
Pot Drain Valve VTP-V-160, or until about 1 gallon of water has been added. been added.

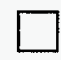

5.2.17 VERIFY the Fan Condensate Drain is functional by observing water exiting the seal pot drain.

5.2.18 POUR water into the Heater Section Condensate Drain until it exits the Seal Pot Drain Valve VTP-V-160, or until 1 gallon of water has been added.

5.2.19 VERIFY the Heater Section Condensate Drain is functional by observing water exiting the seal pot drain. 


\subsection{CONDENSATE DRAIN TEST (Continued)}

5.2.20 VERIFY the Seal Pot Overflow is functional by observing water exiting the Seal Pot 0verflow Valve VTP-V-161.

5.2.21 CLOSE the Seal Pot Overflow valve VTP-V-161.

5.2.22 CLOSE the Seal Pot Drain Valve VTP-V-160.

5.2.23 INSTALL the $1^{\text {st }} \& 2^{\text {nd }}$ stage HEPA filter and Pre-filter access doors UNLESS acceptance testing, including section 5.3 , wi11 continue.

5.2.24 Test Director SHALL VERIFY that section $\mathbf{5 . 1}$ is COMPLETE by SIGNING below.

Test Director Signature Date 


\subsection{PRESSURE DECAY TEST}

5.3.1 PERFORM the following inspections.

5.3.1.1 REMOVE fitter housing doors.

5.3.1.2 REPAIR components as noted on the Exception Resolution.

5.3.1.3 TIGHTEN filter housing door latches in a gradual, equal sequence to ensure an even door gasket seal.

5.3.2 CLOSE Filter train Inlet valve VTP-V-135.

5.3.3 CLOSE Filter train outlet valve VTP-V-136.

5.3.4 VERIFY Seal Pot VTP-SP-001 is empty by opening the seal pot drain valve VTP-V-160.

5.3.5 VERIFY Seal Pot Fill Valve VTP-V-159 is CLOSED.

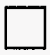

5.3 .5 VERIFY Seal Pot Fill Valve VTP-V-15g is CLOSED.

5.3.6 VERIFY Seal Pot Overflow Drain Line Valve VTP-V-I61 is CLOSED.

5.3.7 CLOSE Seal Pot Drain Valve VTP-V-160.

5.3.8 VERIFY Fan Drain Line Valve VTP-V-158 is CLOSED.

5.3.9 UNSCREW cap on the first stage HEPA Filter Aerosol Injection Port VTP-FTP-002 on the test section next to the Prefilter.

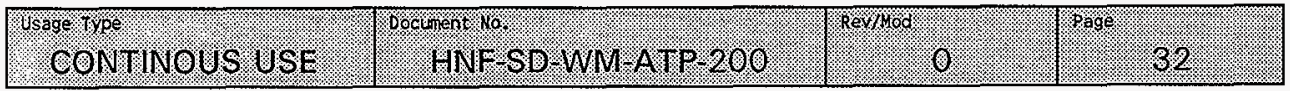




\subsection{PRESSURE DECAY TEST (Continued)}

5.3.10 INSTALL AND SEAL the pressure measuring device into the first stage HEPA Filter Aerosol Injection Port VTP-FTP-002.

5.3.11 INSTALL the air supply line (with safety relief mechanism, isolation valve, and pressure reducer) into the second stage HEPA Fjlter Aerosol Test Port VTP-FTP-003.

NOTE: Next step starts checking positive pressure decay.

5.3.12 PRESSURIZE housing/duct assembly to $+11.5 \pm 0.5$ in $\mathrm{wg}$.

5.3.13 MAINTAIN constant pressure unti] temperature remains constant within $\pm 0.5^{\circ} \mathrm{F}$ as indicated by VTP-TI-179 for a minimum of 10 minutes.

5.3.14 ISOLATE the air supply from the filter housing while STARTING the clock.

5.3.15 RECORD the initial time, barometric pressure, housing pressure, and temperature on Data Sheet 1 (Weather Station 373-2716). 


\section{TANK FARIV ACCEPTANCE TEST PROCEDURE}

\subsection{PRESSURE DECAY TEST (Continued)}

5.3.16 RECORD pressure and temperature readings a minimum of once a minute, until pressure decays to $75 \%$ of the recorded starting pressure (previous step) or for a maximum of 15 minutes, which ever comes first on the following table.

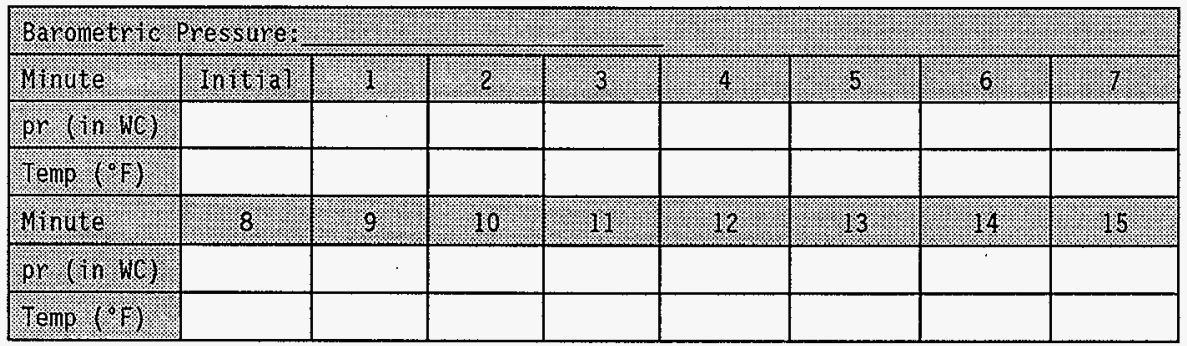

5.3.17 RECORD final time, barometric pressure, and temperature on Data Sheet 1 .

5.3.18 PERFORM the leak rate calculations per Data Sheet 1.

5.3.19 ENSURE the leak rate calculations are verified independently by QC.

5.3.20 If $Q<L_{s}$ then RECORD "PASS" on Data Sheet 1. Otherwise, RECORD "RETEST" on Data Sheet 1. 


\subsection{PRESSURE DECAY TEST (Continued)}

5.3.21 If a retest is needed, then PERFORM the following:

5.3.21.1 REPEAT steps 5.2.14 through 5.2.24 using new data sheets

5.3.22 DISCONNECT the air supply.

5.3.23 SLOWLY RELIEVE pressure from Filter Train housing through valve manifold assembly.

5.3.24 CONNECT a vacuum source to the Pressure Test Assembly at Aerosol Injection Port VTP-FTP-003.

NOTE: Next step starts checking negative pressure decay.

5.3.25 DECREASE Filter Train housing internal pressure to $-11.5 \pm 0.5$ IN W.C. as INDICATED by the Pressure measuring device.

5.3.26 MAINTAIN constant pressure unti] temperature remains constant within $\pm 0.5^{\circ} \mathrm{F}$ for a minimum of 10 minutes.

5.3.27 ISOLATE the vacuum source from the filter housing while starting the clock.

5.3.28 RECORD the initial time, barometric pressure, pressure, and temperature on Data Sheet 2 (Weather Station 373-2716). 


\subsection{PRESSURE DECAY TEST (Continued)}

5.3.29 RECORD pressure and temperature readings a minimum of once a minute, UNTIL pressure decays to $75 \%$ of the recorded starting pressure (previous step) or for a maximum of 15 minutes, which ever comes first on the following table.

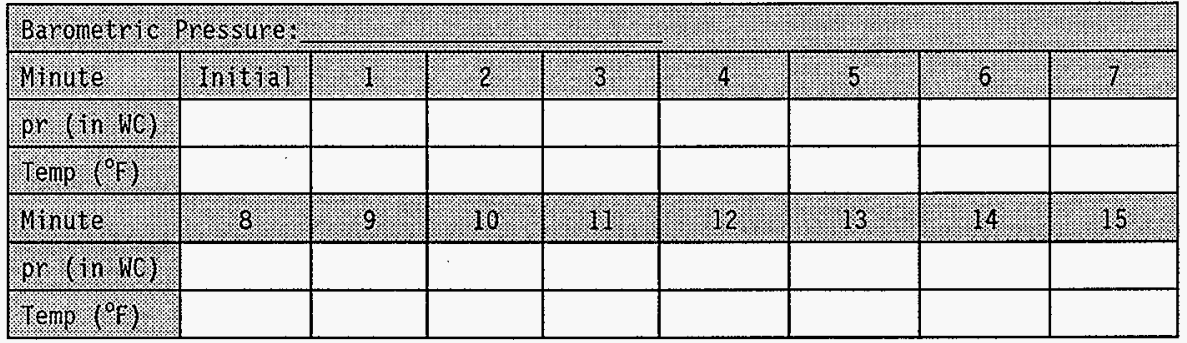

5.3.30 RECORD final time, barometric pressure, and temperature on Data Sheet 2 .

5.3.31 PERFORM the Teak rate calculations per Data Sheet 2.

5.3.32 ENSURE the leak rate calculations are verified independently by QC.

5.3.33 IF $Q<L_{s}$ then RECORD "PASS" on Data Sheet 2 AND GO TO step 5.2.36. "Otherwise, RECORD "RETEST" on Data Sheet 2. 


\subsection{PRESSURE DECAY TEST (Continued)}

5.3.34 IF a retest is needed, then PERFORM the following:

5.3.34.1 DETERMINE the Teak path(s) and REPAIR leaks as noted on the Exception Resolution.

5.3.34.2 REPEAT steps 5.2.28 through 5.2.37 using new data sheets.

5.3.35 DISCONNECT the test equipment.

5.3.36 SLOLY equalize Filter Train housing pressure to atmospheric
through the valve manifold assembly.

5.3.36 SLOLY equalize Filter Train housing pressure to atmospheric
through the valve manifold assembly.

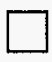

sheets.

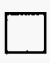

\section{3 .35 DISCONKCT the test equipment.} through the valve manifold assembly.

5.3.37 REINSTALL the test port plugs.

5.3.38 OPEN Fi]ter Train Inlet valve VTP-V-135.

5.3.39 OPEN Filter Train outlet valve VTP-V-136.

5.3.40 OPEN Fan Drain Line Valve VTP-V-158.

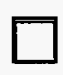




\subsection{EXHAUSTER FAN CHECK}

\subsubsection{INSTALL a11 filters.}

\begin{tabular}{|c|c|c|}
\hline triter? position & int ter vimber: & 19racer in \\
\hline Prye $=170$ & y.P. $=0.001$. & \\
\hline 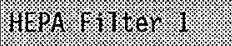 & 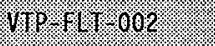 & \\
\hline MERPA I I Y teer ? & WPIILT 003 & \\
\hline
\end{tabular}

5.4.2 POSITION the EXHAUSTER FAN MOTOR DISCONNECT SWITCH VTP-DS-102 to ON.

5.4.3 VERIFY Fan VTP-EF-001 does NOT start automatically.

5.4.4 VERIFY Green FAN OFF 1ight (located on door of Exhauster Control Cabinet VTP-CP-105) is ILLUMINATED.

5.4.5 VERIFY Red FAN RUNNING 7ight (10cated on door of Exhauster Control Cabinet VTP-CP-105) is NOT ILLUMINATED.

5.4.6 POSITION Fan/Off/Enable Control Switch VTP-HS-103 to "ENABLE" position (located on door of Exhauster Control Cabinet VTP-CP105).

5.4.7 PRESS Fan Start Button VTP-PB-101 AND THEN QUICKLY PRESS Fan Stop Button VTP-PB-102 (i.e. bump the fan) (located on door of Exhauster Control Cabinet VTP-CP-105).

5.4.8 VERIFY that direction of rotation of the Exhaust fan VTP-EF-001 shaft is in the DIRECTION of the arrow on the fan housing or motor shroud. 


\subsection{EXHAUSTER FAN CHECK (Continued)}

5.4.9 IF Exhauster Fan VTP-EF-001 rotation direction is correct, G0 TO step 5.4.11

5.4.10 IF direction of rotation of the Exhauster Fan VTP-EF-001 is in the incorrect direction, then PERFORM the following:

5.4.10.1 DO NOT EXECUTE any further part of 5.3 in this ATP UNTIL next step through 5.4 .10 .5 are COMPLETED.

5.4.10.2 POSITION Fan Motor Disconnect Switch VTP-DS-102A to OFF.

5.4.10.3 INSTALL Personal Locking Device on Fan Motor Disconnect Switch VTP-DS-102.

5.4.10.4 CORRECT the Exhauster Fan VTP-EF-001 rotation direction by CORRECTING the leads at the Fan Motor Disconnect Switch VTP-DS-101.

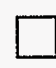




\section{TANK FARM ACGEPTANCE TEST PROCEDURE}

\subsection{EXHAUSTER FAN CHECK (Continued)}

5.4.11 OPEN the High and Low valves AND CLOSE Equalizing valve on each three valve manifold for the following DPTs:

\begin{tabular}{|c|c|c|c|c|c|c|}
\hline 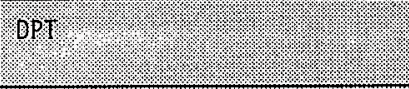 & valve $19:$ & (1) & Vilice & Open: & Vove & ( \\
\hline 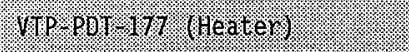 & (1. 137 & & 1.138 & & 1.139 & \\
\hline yTP-PDT 178 ( Ire-tinter) & 1.140 & & $18.141:$ & & 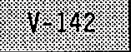 & \\
\hline VIP-PBI. 180 (1) IIEPf) & 1.1 .14 & & $=1 / 2.144$ & & $.17 .145:$ & \\
\hline 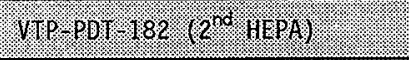 & .1 .149 & & 150 & & V. & \\
\hline 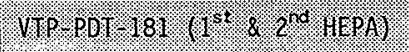 & 1.146 & & 1.147 & & $1.148=$ & \\
\hline
\end{tabular}

5.4.12 POSITION Fan Motor Disconnect Switch VTP-DS-102 to OFF.

5.4.13 REMOVE Fan VTP-EF-001 shaft guard as required to allow access to shaft bearings.

5.4.14 POSITION Fan Motor Disconnect Switch VTP-DS-101 to ON.

5.4.15 CONNECT operation control console (computer) to the SLC 500 CPU.

5.4.16 FORCE the exhaust SLC Program to run the exhaust fan at $3450 \mathrm{rpm}$.

5.4.17 POSITION Fan/Off/Enable Control Switch VTP-HS-103 to "ENABLE" position (located on door of Exhauster Control Cabinet VTP-CP105). 


\subsection{EXHAUSTER FAN CHECK (Continued)}

5.4.18 PRESS Fan Start Button VTP-PB-101 (Located on door of Exhauster Control Cabinet VTP-CP-105) to turn ON Exhauster Fan VTP-EF-001.

5.4.19 VERIFY Green FAN OFF light (located on door of Exhauster Control Cabinet VTP-CP-105) is NOT ILLUMINATED.

5.4.20 VERIFY Red FAN RUNNING 1 ight (10cated on door of Exhauster Control Cabinet VTP-CP-105) is ILLUMINATED.

5.4.21 ENSURE fan is operating normally with no unusual noise.

NOTE - Next step starts the Exhauster Fan VTP-EF-001 vibration test. The testing is based on ASME N509 requirements for $3450 \mathrm{rpm}$.

5.4.22 USING the vibration instrument, RECORD the measured data in the table at next step.

\begin{tabular}{|c|c|c|c|c|c|c|}
\hline (4) & faxal & $(6)$ & $161.4014=$ & 0 & 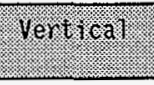 & $(10 \%$ \\
\hline 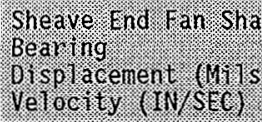 & & & & & & \\
\hline 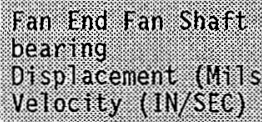 & & & & & & \\
\hline
\end{tabular}




\subsection{EXHAUSTER FAN CHECK (Cont inued)}

5.4.23 VERIFY that the Filtered Bearing Vibration Levels on the fan shaft bearings should meet the following criteria:

- Displacement <.6 MILS (PK-TO-PK) at one times the fan speed.

$$
\text { - } O R \text { - }
$$

- Velocity <.11 IN/SEC (PK) at one times the fan speed.

5.4.24 PRESS Fan Stop Button VTP-PB-102 (located on door of Exhauster Control Cabinet VTP-CP-105) to turn OFF Exhauster Fan.

5.4.25 VERIFY Exhauster fan has SHUTDOWN.

5.4.26 REMOVE force from the exhauster SLC Program.

5.4.27 POSITION Fan Motor Disconnect Switch VTP-DS-102 to OFF.

5.4.28 REPLACE Fan VTP-EF-001 shaft guard.

5.4.29 POSITION Fan Motor Disconnect Switch VTP-DS-102 to ON.

5.4.30 Test Director SHALL VERIFY that section 5.4 is COMPLETE by SIGNING below.

$\overline{\text { Test Director Signature }}$

$\overline{\text { Date }}$

\begin{tabular}{|c|c|c|c|}
\hline Usag TONTINOUS USE. & INIF SE WW ATP 200 & 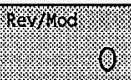 & Tige \\
\hline
\end{tabular}




\subsection{HEAT TRACE CHECK}

5.5.1 ENSURE Heat Trace 120V circuit breaker \#4 (10cated at MPZ Cabinet VTP-PNL-101) is ON.

5.5.2 USING a DMM, VERIFY $0 \mathrm{~V}$ at termina7s TB1HTC-11 and TB2HTC-11 (located at Heat Trace Cabinet VTP-ENCL-104).

5.5.3 IMMERSE Heat trace thermostat probe in ice.

5.5.4 WAIT 2-5 minutes.

5.5.5 USING a DMM, VERIFY $120 \mathrm{~V}$ at terminals TB1HTC-11 and TB2HTC-11 (located at Heat Trace Cabinet VTP-ENCL-104).

5.5.6 VERIFY Heat Trace ON amber light (located at door of Heat Trace Cabinet VTP-ENCL-104) is ILLUMINATED.

5.5.7 REMOVE ice from the heat trace thermostat probe.

5.5.8 VERIFY Heat Trace ON amber light (located at door of Heat Trace Cabinet VTP-ENCL-104) is NOT ILLUMINATED after probe heats up.

5.5.9 USING a DMM, VERIFY $0 \mathrm{~V}$ at terminals TBIHTC-11 and TB2HTC-1I

(1ocated at Heat Trace Cabinet VTP-ENCL-104).

5.5.10 POSITION Heat Trace 120V circuit breaker \#4 (located at MPZ Cabinet VTP-PNL-101) to OFF. (1)

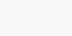

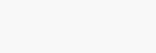

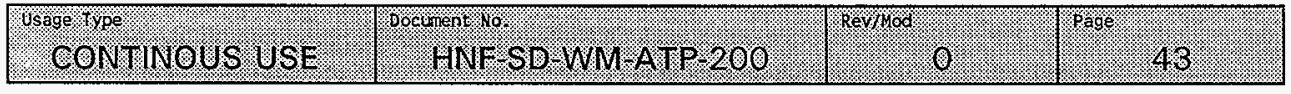




\subsection{HEAT TRACE CHECK (Continued)}

5.5.11 Test Director SHALL VERIFY that section 5.5 is COMPLETE by SIGNING below.

$\overline{\text { Test Director Signature }}$

$\overline{\text { Date }}$

\begin{tabular}{|c|c|c|c|}
\hline 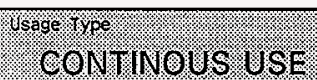 & 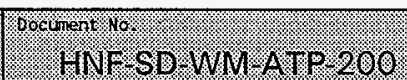 & 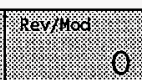 & T: \\
\hline
\end{tabular}




\subsection{FILTER \#1 DP INTERLOCK/ALARM CHECK (Transmitter Range 0-10")}

5.6.1 ENSURE the High, Low and Equalizing valve on VTP-DPT-180's three valve manifold are CLOSED or OPEN as indicated below:

\begin{tabular}{|c|c|c|c|c|c|c|}
\hline opt: & Wye & (2) & 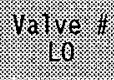 & open & Wave & (10sids \\
\hline VIP. per 180 & 1.179 & & $y=449$ & & $y-145$ & \\
\hline
\end{tabular}

5.6.2 REMOVE back cover from VTP-PDT-180.

5.6.3 CONNECT a BT-200 to the transmitter VTP-PDT-180.

5.6.4 ENSURE Fan/Off/Enable Control Selector Switch VTP-HS-103 (1ocated on door of Exhauster Control Cabinet VTP-CP-105) is in the Enable position.

5.6.5 PRESS Fan Start Button VTP-PB-101 (located on door of Exhauster Control Cabinet VTP-CP-105).

5.6.6 WAIT for the Exhauster fan to come up to speed.

5.6.7 SET the BT-200 to test at $045.0 \%$. This is equal to 4.5 IN W.C. 


\subsection{FILTER \#1 DP INTERLOCK/ALARM CHECK (Continued)}

5.6.8 VERIFY the following:

- Clear Rotating Beacon VTP-XA-101 is ILLUMINATED.

- Red Fan RUNNing light is illuminated.

- Green FAN OFF Tight is NOT ILLUMINATED.

- Message View Displays VTP-MV-101 and VTP-MV-102 (located at Alarm Cabinet Swing Out Panel) DISPLAY "FILTER 1 DP HI".

5.6.9 RECORD the pressure indicated by the Wilkerson indicator VTP-PDI180 (located on door of Exhauster Control Cabinet VTP-CP-105).

Indicated Pressure:

5.6.10 ACKNOWLEDGE the alarm by PRESSING the 1 button, then pressing the "+" button on the Message View Display VTP-MV-101 (10cated at Alarm Cabinet VTP-ENCL-107 Swing out Pane1) three times. For any secondary alarms repeat this step until all alarms are cleared.

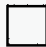

5.6.11 VERIFY Clear Rotating Beacon VTP-XA-101 is NOT ILLUMINATED.

5.6.12 VERIFY Message View Display VTP-MV-102 (located at Alarm Cabinet Swing Out Pane1) STILL DISPLAYS "FILTER I DP HI". Any secondary alarms that are still in alarm condition will al so be indicated.

5.6.13 SET the BT-200 to test at $054.0 \%$. This is equivalent to 5.4 IN W.C. 


\subsection{FILTER \#1 DP INTERLOCK/ALARM CHECK (Continued)}

\subsubsection{VERIFY the following:}

- Exhauster Fan VTP-EF-001 has SHUTDOWN.

- Red fan RUNning light is NOT Illuminated.

- Green FAN OFF light is ILluMinated.

- Clear Rotating Beacon VTP-XA-101 (located on stack supporting framing) is ILLUMINATED.

- Message View Display VTP-MV-101 (located at Alarm Cabinet Swing out Pane1) DISPLAYS "FILTER 1 DP HIHI". Any secondary alarms that are still in alarm condition will also be indicated.

5.6.15 RECORD the pressure indicated by the Wilkerson indicator VTP.PDI180 (located on door of Exhauster Control Cabinet VTP-CP-105).

Indicated Pressure:

5.6.16 ACKNOWLEDGE the alarm by PRESSING the "1" button, then pressing the " + " button on the Message View DispIay VTP-MV-101 (located at Al arm Cabinet VTP-ENCL-107 Swing Out Panel) three times. For any secondary alarms repeat this step until all alarms are cleared

5.6.17 VERIFY Clear Rotating Beacon VTP-XA-101 is NOT ILLUMINATED. 


\subsection{FILTER \#1 DP INTERLOCK/ALARM CHECK (Continued)}

5.6.18 VERIFY Message View Display VTP-MV-102 (located at Alarm Cabinet Swing out Pane1) STILL DISPLAYS "FILTER 1 DP HIHI". Note: Any secondary alarms that are still in alarm condition will also be indicated.

5.6.19 CLEAR the BT-200 test setting.

5.6.20 FORCE the rate of change logic.

5.6.21 PRESS Fan Start Button PB-101 (located on door of Exhauster Control Cabinet VTP-CP-105).

5.6.22 WAIT for the Exhauster fan to come up to speed.

5.6.23 SET the BT-200 to test at $000.9 \%$. This is equivalent to approximately 0.1 IN W.G.

WAIT for the Exhauster fan to come up to speed. 


\subsection{FILTER \#1 DP INTERLOCK/ALARM CHECK (Cont inued)}

5.6.24 VERIFY the following:

- Exhauster Fan VTP-EF-00I has SHUTDOWN after 10 seconds.

- Red fan RUNNING Tight is NOT ILLUMINATED.

- Red FAN RUNING Tight is NOT ILLUMINATED.

- Green fan ofF light is IlLUMinated.

- Clear Rotating Beacon VTP-XA-101 (located on stack supporting framing) is ILLUMINATED.

- Message View Display VTP-MV-101 and VTP-MV-102 (located at Alarm Cabinet Swing Out Pane1) DISPLAYS "Filter 1 ROC" and "FILTER 1 DP LO". Any secondary alarms that are still in alarm condition will also be indicated.

5.6.25 ACKNOWLEDGE the alarm by PRESSING the "1" button, then pressing the "r" button on the Message View Display VTP-MV-101 (10cated at Alarm Cabinet VTP-ENCL-107 Swing Out Panel) three times. For any secondary alarms repeat this step until all alarms are cleared

5.6.26 VERIFY Clear Rotating Beacon VTP-XA-101 is NOT ILLUMINATED.

5.6.27 CLEAR the BT-200 test setting. 
5.6 FILTER \#1 DP INTERLOCK/ALARM CHECK (Cont inued)

5.6.28 REMOVE force on the rate of change logic.

5.6.29 PRESS the Fan Start Button PB-101 (located on the door of Exhauster Control Cabinet VTP-CP-105).

5.6.30 WAIT 2 minutes for the fan to come up to speed.

5.6.31 RECORD VTP-PDT-180 reading.

Reading:

5.6.32 SET the BT-200 to test at 0.5 IN W.C. less then the value recorded in the previous step from transmitter VTP-PDT-180.

5.6.33 RECORD the BT-200 setting.

Setting:

\begin{tabular}{|c|c|c|c|}
\hline isase Tyo CONTINOUS USE & 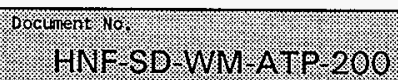 & Reyrom & fioger: $=5$ \\
\hline
\end{tabular}




\subsection{FILTER \#1 DP INTERLOCK/ALARM CHECK (Continued)}

\subsubsection{VERIFY the following:}

- Clear rotating beacon VTP-XA-101 is ILLUMINATED.

- Red fan running light is NOT ILLUMINATED.

- Green fan off light is ILLUMINATED.

- Exhauster fan VTP-EF-001 has shutdown.

- Message view display VTP-MV-101 (10cated at alarm cabinet swing out pane1) DISPLAYS "Fi1ter I DP ROC". Any secondary al arms that are still in alarm condition will also be indicated.

5.6.35 ACKNOWLEDGE the alarm by PRESSING the "1" button, then pressing the "s" button on the Message View Display VTP-MV-101 (located at Alarm Cabinet VTP-ENCL-107 Swing Out Panel) three times. For any secondary alarms repeat this step until all alarms are cleared

5.6.36 VERIFY Clear Rotating Beacon VTP-XA-101 is NOT ILLUMINATED.

5.6.37 DISCONNECT BT-200 from transmitter VTP-PDT-180.

5.6.38 REPLACE back cover on transmitter VTP-PDT-180.

5.6.39 Test Director SHALL VERIFY that section 5.6 is COMPLETE by SIGNING below.

Test Director Signature

$\overline{\text { Date }}$ 


\section{TANK FARM ACCEPTANGE TEST PROQEDURE}

\subsection{FILTER \#2 DP INTERLOCK/ALARM CHECK (Transmitter Range 0-6")}

5.7.1 ENSURE the High, Low and Equalizing valves on VTP-DPT-182 three valve manifold are CLOSED or OPEN as indicated below:

\begin{tabular}{|c|c|c|c|c|c|c|}
\hline 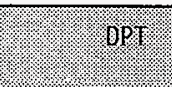 & Wally- It & OPI) & V.aline $\#=0$ & (1) & 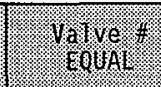 & 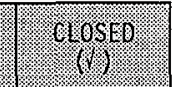 \\
\hline VIP - PBI 182 & V. 1.149 & & 1. 1. 150 & & (3. & \\
\hline
\end{tabular}

5.7.2 REMOVE back cover from the transmitter VTP-PDT-182.

5.7.3 CONNECT a BT-200 to the transmitter VTP-PDT-182.

5.7.4 ENSURE Fan/Off/Enable Control Selector Switch VTP-HS-103 (located on door of Exhauster Control Cabinet VTP-CP-105) is in the Enable position.

5.7.5 PRESS Fan Start Button PB-101 (located on door of Exhauster Control Cabinet VTP-(P-105).

5.7.6 WAIT for the Exhauster fan to come up to speed.

5.7.7 SET BT-200 to test at $053.4 \%$. This is equivalent to 3.2 IN W.C. 


\subsection{FILTER \#2 DP INTERLOCK/ALARM CHECK (Continued)}

5.7.8 VERIFY the following:

- Clear Rotating Beacon VTP-XA-101 is ILLUMINATED.

- Red fan running light is Illuminated.

- Green FAN OFF light is NOT ILLUMINATED.

- Message View Displays VTP-MV-101 and VTP-MV-102 (located at Al arm Cabinet Swing Out Panel) DISPLAY "FILTER 2 DP HI".

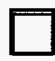

5.7.9 RECORD value from Wilkerson indicator VTP-PDI-182 (located on door of Exhauster Control Cabinet VTP-CP-105).

READING:

IN W.C.

5.7.10 ACKNOWLEDGE the alarm by PRESSING the "1" button, then pressing the "ه" button on the Message View Display VTP-MV-101 (located at Alarm Cabinet VTP-ENCL-107 Swing Out Panel) three times. For any secondary alarms repeat this step until all alarms are cleared.

5.7.11 VERIFY Clear Rotating Beacon VTP-XA-101 is NOT ILLUMINATED.

5.7.12 VERIFY Message View Display VTP-MV-102 (1ocated at Alarm Cabinet Swing out Panel) STILL DISPLAYS "FILTER 2 DP HI".

5.7.13 SET the BT-200 to test at $061.7 \%$. This is equivalent to 3.7 IN
W.C.

5.7.13 SET the BT-200 to test at $061.7 \%$. This is equivalent to 3.7 IN
W.C.

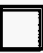




\subsection{FILTER \#2 DP INTERLOCK/ALARM CHECK (Continued)}

5.7.14 VERIFY the following:

- Exhauster Fan VTP-EF-001 has SHUTDOWN.

- Red FAN RUNNING light is NOT ILLUMINATED.

- Green fan OFF light is ILLUMINATED.

- Clear Rotating Beacon VTP-XA-101 (located on stack supporting framing) is ILLUMINATED.

- Message View Display VTP-MV-101 (located at Alarm Cabinet Swing Out Panel) DISPLAYS "FILTER 2 DP HIHI". Any secondary alarms that are still in alarm condition will also be indicated.

5.7.15 RECORD value from Wilkerson indicator VTP-PDI-182 (located on door of Exhauster Control Cabinet VTP-CP-105).

READING:

IN W.C.

5.7.16 ACKNOWLEDGE the a1arm by PRESSING the " 1 " button, then pressing the " $\leftrightarrow$ " button on the Message View Display VTP-MV-101 (located at Alarm Cabinet VTP-ENCL-107 Swing Out Pane1) three times. For any secondary alarms repeat this step until all alarms are cleared.

5.7.17 VERIFY Clear Rotating Beacon VTP-XA-101 is NOT ILLUMINATED.

5.7.18 VERIFY Message View Display VTP-MV-102 (Tocated at Alarm Cabinet Swing out Panel) STILL DISPLAYS "FILTER 2 DP HIHI". Any secondary alarms that are still in alarm condition will also be indicated. 


\subsection{FILTER \#2 DP INTERLOCK/ALARM CHECK (Continued)}

5.7.19 CLEAR the BT-200 test setting.

5.7.20 FORCE the rate of change logic.

5.7.21 PRESS Fan Start Button VTP-PB-101 (1ocated on door of Exhauster Control Cabinet VTP-CP-105).

5.7.22 WAIT for the Exhauster fan to come up to speed.

5.7.23 SET the BT-200 to test at $001.6 \%$. This is equivalent to 0.1 IN W.C.

5.7.24 VERIFY the following:

- Exhauster Fan VTP-EF-001 has SHUTDOWN after 10 seconds.

- Red fan RUNNing light is nOt ILluminated.

- Green fan OFF light is Illuminated.
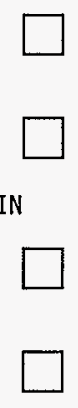


\subsection{FILTER \#2 DP INTERLOCK/ALARM CHECK (Continued)}

5.7.25 ACKNOWLEDGE the a] arm by PRESSING the " 1 " button, then PRESSING the " $"$ " button on the Message View Display VTP-MV-101 (located at Alarm Cabinet VTP-ENCL-107 Swing Out Pane1) three times. For any secondary alarms repeat this step until all alarms are cleared.

5.7.26 VERIFY Clear Rotating Beacon VTP-XA-101 is NOT ILLUMINATED.

5.7.27 CLEAR the BT-200 test setting.

5.7.28 REMOVE force on the rate of change logic.

5.7.29 PRESS the Fan Start Button PB-101 (located on the door of Exhauster Control Cabinet VTP-CP-105).

5.7.30 WAIT 2 minutes for the fan to come up to speed.

5.7.31 RECORD VTP-PDT-182 reading.

Reading:

5.7.32 SET the BT-200 to test at 0.5 IN W.C. less then the value recorded in the previous step from transmitter VTP-PDT-182.

5.7.33 RECORD the BT-200 setting.

Setting: 


\subsection{FILTER \#2 DP INTERLOCK/ALARM CHECK (Continued)}

5.7.34 VERIFY the following:

- Clear rotating beacon VTP-XA-101 is ILLUMINATED.

- Red fan running light is NOT ILLUMINATED.

- Green fan off light is ILLUMinATED.

- Exhauster fan VTP-EF-001 has shutdown.

- Message view display VTP-MV-101 (located at alarm cabinet swing out panel) DISPLAYS "Filter 2 DP ROC". Any secondary alarms that are still in alarm condition will also be indicated.

5.7.35 ACKNOWLEDGE the alarm by PRESSING the "1" button, then pressing the "w" button on the Message View Display VTP-MV-101 (located at Alarm Cabinet VTP-ENCL-107 Swing Out Panel) three times. For any secondary alarms repeat this step until all alarms are cleared

5.7.36 VERIFY Clear Rotating Beacon VTP-XA-101 is NOT ILLUMINATED.

5.7.37 RESET BT-200.

5.7.38 DISCONNECT BT-200 from transmitter VTP-PDT-182. 


\subsection{FILTER \#2 DP INTERLOCK/ALARM CHECK (Continued)}

5.7.39 REPLACE back cover on transmitter VTP-PDT-182.

5.7.40 Test Director SHALL VERIFY that section 5.7 is COMPLETE by SIGNING below.

Test Director Signature

Date 
5.8 FILTER \# 1 \& \#2 DP INTERLOCK/ALARM CHECK (Transmitter Range 06")

5.8.1 ENSURE the High, Low and Equalizing valves on VTP-DPT-181 three valve manifold are CLOSED or OPEN as indicated below:

\begin{tabular}{|c|c|c|c|c|c|c|}
\hline (2.: & val $10=4$ & OPEN & $\frac{1910}{160}$ & (opt) & $\begin{array}{l}\text { valvert: } \\
\text { Equal : }\end{array}$ & (agsebl: \\
\hline 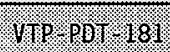 & $\sqrt{146}$ & & $y=47$ & & 17.148 & \\
\hline
\end{tabular}

5.8.2 REMOVE back cover on the transmitter VTP-PDT-181.

5.8.3 CONNECT a BT-200 to the transmitter VTP-PDT-181.

5.8.4 ENSURE Fan/Off/Enable Control Selector Switch VTP-HS-103 (located on door of Exhauster Control Cabinet VTP-CP-105) is in the Enable position.

5.8.5 PRESS Fan Start Button VTP-PB-101 (7ocated on door of Exhauster Control Cabinet VTP-CP-105).

5.8.6 WAIT for the Exhauster fan to come up to speed.

5.8.7 SET the BT-200 to test at $090.1 \%$. This is equivalent to 5.4 IN

W.C.

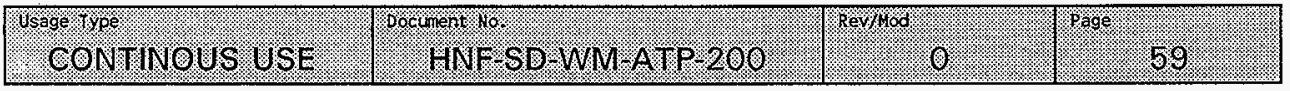




\section{TANK FARM ACCEPTANCE TEST PROCEDURE}

\subsection{FILTER \#1 \& \#2 DP INTERLOCK/ALARM CHECK (Continued)}

\subsubsection{VERIFY the following:}

- Exhauster Fan VTP-EF-001 has SHUTDOWN.

- Red FAN RUNNING light is NOT ILLUMINATED.

- Green fan OFF light is ILluMinated.

- Clear Rotating Beacon VTP-XA-101 (1ocated on stack supporting framing) is ILLUMINATED.

- Message View Display VTP-MV-101 (located at Alarm Cabinet Swing out Pane1) DISPLAYS "FILTERS 1 \& 2 DP HIHI". Any secondary alarms that are still in alarm condition will also be indicated.

- Message View Display VTP-MV-102 (located at Alarm Cabinet Swing Out Pane1) DISPLAYS "FILTERS 1 \& 2 DP HIHI" secondary alarms that are still in alarm condition will also be indicated.

5.8.9 RECORD value from Wilkerson indicator VTP-PDI-181 (located on door of Exhauster Control Cabinet VTP-CP-105).

READING:

IN W.C.

5.8.10 ACKNOWLEDGE the alarm by PRESSING the "1" button, then pressing the " $\rightarrow$ " button on the Message View Display VTP-MV-101 (10cated at Al arm Cabinet VTP-ENCL-107 Swing Out Pane1) three times. For any secondary alarms repeat this step until all alarms are cleared.

5.8.11 VERIFY Clear Rotating Beacon VTP-XA-101 is NOT ILLUMINATED. 


\subsection{FILTER \#1 \& \#2 DP INTERLOCK/ALARM CHECK (Continued)}

5.8.12 VERIFY Message View Display VTP-MV-102 (located at Alarm Cabinet Swing out Panel) STILL DISPLAYS "FILTER 1\&2 DP HIHI". Any secondary alarms that are still in alarm condition will also be indicated.

5.8.13 CLEAR the BT-200 test setting.

5.8.14 FORCE the rate of change logic.

5.8.15 PRESS Fan Start Button VTP-PB-101 (located on door of Exhauster Control Cabinet VTP-CP-105).

5.8.16 WAIT for the Exhauster fan to come up to speed.

5.8.17 SET the BT-200 to test at $001.6 \%$. This is equivalent to

\section{approximately 0.1 IN W.C.}




\subsection{FILTER \#1 \& \#2 DP. INTERLOCK/ALARM CHECK (Continued)}

5.8.18 VERIFY the following:

- Exhauster Fan VTP-EF-001 has SHUTDOWN after 10 seconds.

- Red Fan RUNNING 1 ight is NOT ILlUMinAted.

- Green fan OFF light is Illuminated.

- Clear Rotating Beacon VTP-XA-101 (located on stack supporting framing) is ILLUMINATED.

- Message View Display VTP-MV-101 (10cated at Alarm Cabinet Swing Out Pane1) DISPLAYS "Filter 1\&2 ROC" and "FILTER 1\&2 DP LO". Any secondary alarms that are still in alarm condition will also be indicated.

- Message View Display VTP-MV-102 (located at Alarm Cabinet Swing Out Pane1) DISPLAYS "FILTER 1\&2 DP LO". Any secondary alarms that are still in alarm condition will also be indicated.

5.8.19 ACKNOWLEDGE the alarm by PRESSING the " 1 " button, then three times "+s" button on the Message View Display VTP-MV-101 (located at Alarm Cabinet VTP-ENCL-107 Swing Out Pane1). For any secondary alarms repeat this step until all alarms are cleared.

5.8.20 VERIFY Clear Rotating Beacon VTP-XA-101 is NOT ILLUMINATED.

5.8.21 CLEAR the BT-200 test setting.

5.8.22 REMOVE force on the rate of change logic. 


\subsection{FILTER \# 1 \& \#2 DP INTERLOCK/ALARM CHECK (Continued)}

5.8.23 PRESS the Fan Start Button PB-101 (located on the door of Exhauster Control Cabinet VTP-CP-105).

5.8.24 WAIT approximately 2 minutes for the fan to come up to speed.

5.8.25 RECORD VTP-PDT-181 reading.

Reading:

5.8.26 SET the BT-200 to test at $<0.5$ IN W.G. of VTP-PDT-181 reading.

5.8.27 RECORD the BT-200 setting.

Setting:

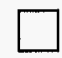




\subsection{FILTER \# 1 \& \#2 DP INTERLOCK/ALARM CHECK (Continued)}

\subsubsection{VERIFY the following:}

- Clear rotating beacon VTP-XA-101 is ILLUMINATED.

- $\quad$ Red fan running Tight is NOT ILLUMINATED.

- Green fan off light is ILLUMINATED.

- Exhauster fan VTP-EF-001 has shutdown.

- Message view display VTP-MV-101 (located at alarm cabinet swing out pane1) DISPLAYS "Filter 1 \& 2 DP ROC": Any secondary alarms that are still in alarm condition will also be indicated.

5.8.29 ACKNOWLEDGE the alarm by PRESSING the " 1 " button, then pressing the "+" button on the Message View Display VTP-MV-101 (located at Alarm Cabinet VTP-ENCL-107 Swing Out Pane1) three times. For any secondary alarms repeat this step until all alarms are cleared

5.8.30 VERIFY Clear Rotating Beacon VTP-XA-101 is NOT ILLUMINATED.

5.8.31 DISCONNECT BT-200 from transmitter VTP-PDT-181.

5.8.32 REPLACE back cover on transmitter VTP-PDT-181. 


\subsection{FILTER \# 1 \& \#2 DP INTERLOCK/ALARM CHECK (Continued)}

5.8.33 Test Director SHALL VERIFY that section 5.8 is COMPLETE by SIGNING below.

$\overline{\text { Test Director Signature }}$

$\overline{\text { Date }}$ 


\section{TANK FARM ACCEPTANCE TEST PROCEDURE}

5.9 PREFILTER DP INTERLOCK/ALARM CHECK (Transmitter Range 0-2")

5.9.1 ENSURE the High, Low and Equalizing valve on VTP-DPT-178 three valve manifold are CLOSED or OPEN as indicated below:

\begin{tabular}{|c|c|c|c|c|c|c|}
\hline ippl: & Vavee It: & - OPEN & $129180=7$ & opex & Valve t: & (crospo. \\
\hline VTe pret 1.8 & $1 / 2.40$. & & $1 / .14 \%$ & & 15.142 & \\
\hline
\end{tabular}

5.9.2 REMOVE back cover on transmitter VTP-PDT-178.

5.9.3 CONNECT a BT-200 to the transmitter VTP-PDT-178.

5.9.4 ENSURE Fan/Off/Enable Control Selector Switch VTP-HS-103 (1ocated on door of Exhauster Control Cabinet VTP-CP-105) is in the Enable position.

5.9.5 PRESS Fan Start Button VTP-PB-101 (1ocated on door of Exhauster Control Cabinet VTP-CP-105).

5.9.6 WAIT for the Exhauster fan to come up to speed.

5.9.7 SET the BT-200 to test at $050.0 \%$. This is equivalent to 1.0 IN W.C. 


\section{TANK FARIM ACCEPTANCE TEST PROCEDURE}

\subsection{PREFILTER DP INTERLOCK/ALARM CHECK (Continued)}

5.9.8 VERIFY the following:

- Clear Rotating Beacon VTP-XA-101 is ILLUMINATED.

- Red FAN RUNNing light is ILLUMinated.

- Green FAN OFF Tight is NOT ILLUMINATED.

- Message View Display VTP-MV-101 (located at Alarm Cabinet Swing out Pane1) DISPLAYS "PRE-FILTER DP HI".

5.9.9 RECORD value from Wilkerson indicator VTP-PDI-178 (located on door of Exhauster Control Cabinet VTP-CP-105).

READING :

IN W.C.

5.9.10 ACKNOWLEDGE the alarm by PRESSING the " 1 " button, then pressing the "+" button on the Message View Display VTP-MV-101 (located at Alarm Cabinet VTP-ENCL-107 Swing Out Pane1) three times. For any secondary alarms repeat this step until all alarms are cleared.

5.9.11 VERIFY Clear Rotating Beacon VTP-XA-101 is NOT ILLUMINATED.

5.9.12 VERIFY Message View Display VTP-MV-102 (located at Alarm Cabinet Swing Out Panel) STILL DISPLAYS "PRE-FILTER DP HI".

5.9.13 DISCONNECT BT-200.

5.9.14 REPLACE back cover on transmitter VTP-PDT-178. 


\subsection{PREFILTER DP INTERLOCK/ALARM CHECK (Continued)}

5.9.15 Test Director SHALL VERIFY that section 5.9 is COMPLETE by SIGNING below.

Test Director Signature

Date 


\subsection{STACK FLOW INTERLOCK/ALARM CHECK}

5.10.1 PRESS Fan Start Button VTP-PB-101 (1ocated on door of Exhauster Control Cabinet VTP-CP-105).

5.10.2 WAIT for the Exhauster fan to come up to speed.

5.10.3 FORCE fan input to 500 CFM.

5.10.4 VERIFY fan operation continues.

5.10.5 RECORD value indicated by Wilkerson indicator VTP-FT-184 (located on door of Exhauster Control Cabinet VTP-CP-105).

READING:

5.10.6 VERIFY Wilkerson indicator VTP-FT-184 (1ocated on door of

Exhauster Control Cabinet VTP-CP-105) is READING within a range of $495 \mathrm{CFM}$ and $505 \mathrm{CFM}$.

5.10.7 FORCE fan input to $530 \mathrm{CFM}$. 


\subsection{STACK FLOW INTERLOCK/ALARM CHECK (Continued)}

\subsubsection{PERFORM the following:}

- RECORD value indicated on WiTkerson indicator VTP-FI-184 (Tocated on door of Exhauster Control Cabinet VTP-CP-105), corresponding to transmitter FT-184.

\section{READING:}

- VERIFY Clear Rotating Beacon VTP-XA-101 (located on stack supporting framing) is ILLUMINATED.

- VERIFY Wilkerson indicator VTP-FI-184 (located on door of Exhauster Control Cabinet VTP-(P-105), corresponding to transmitter FT-184, is READING a flow rate within a range of 525 CFM and 535 CFM.

- VERIFY Message View Display MV-101 and MV-102 (located at Alarm Cabinet Swing Out Pane1) DISPLAYS "STACK FLOW HI".

5.10.9 ACKNOWLEDGE the alarm by PRESSING the " 1 " button, then pressing the " $\leftrightarrow$ " button on the Message View Display VTP-MV-101 (located at A1arm Cabinet VTP-ENCL-107 Swing Out Pane1) three times. For any secondary alarms repeat this step until al1 alarms are cleared.

5.10.10 VERIFY Clear Rotating Beacon VTP-XA-101 is NOT ILLUMINATED.

5.10.11 VERIFY Message View Disp]ay VTP-MV-101 (located at Alarm Cabinet Swing Out Pane1) CLEARS al arm message.

5.10.12 CLEAR force.

5.10.13 PRESS Fan Start Button VTP-PB-101 (located on door of Exhauster Control Cabinet VTP-CP-105). 


\subsection{STACK FLOW INTERLOCK/ALARM CHECK (Continued)}

5.10.14 WAIT for the Exhauster fan to come up to speed.

5.10.15 FORCE rate of change and low flow.

5.10.16 FORCE fan input to $230 \mathrm{CFM}$.

5.10.17 RECORD the value indicated on the Wilkerson indicator VTP-FI-184 (located on door of Exhauster Control Cabinet VTP-CP-105), corresponding to transmitter FT-184.

READING:

5.10.18 VERIFY the Wilkerson indicator VTP-FI-184 (1ocated on door of Exhauster Control Cabinet VTP-(P-105), corresponding to transmitter $\mathrm{FT}-184$, is READING a flow rate within a range of 225 CFM and 235 CFM.

5.10.19 REMOVE rate of change and low flow forces.

5.10.20 VERIFY after 10 second the Clear Rotating Beacon VTP-XA-101 (1ocated on stack supporting framing) is ILLUMINATED. 


\subsection{STACK FLOW INTERLOCK/ALARM CHECK (Continued)}

5.10.21 VERIFY the following after 30 seconds:

- $\quad$ Red fan running light is NOT ILLUMINATED.

- Green fan off light is ILLUMINATED.

- Exhauster fan VTP-EF-001 has shutdown.

- Message View Display VTP-MV-101 and VTP-MV-102 (located at Alarm Cabinet Swing out Panel) DISPLAYS "STACK FLOW L0".

5.10.22 ACKNOWLEDGE the alarm by PRESSING the "1" button, then PRESSING the "ه" button on the Message View Display VTP-MV-101 (located at Alarm Cabinet VTP-ENCL-107 Swing Out Pane1) three times. For any secondary alarms repeat this step until all alarms are cleared.

5.10.23 VERIFY Clear Rotating Beacon VTP-XA-101 is NOT ILLUMINATED.

5.10.24 VERIFY Message View Display VTP-MV-101 (located at Alarm Cabinet Swing Out Panel) CLEARS alarm message.

5.10.25 REMOVE a17 fan input forces.

5.10.26 Test Director SHALL VERIFY that section 5.10 is COMPLETE by SIGNING below.

Test Director Signature

Date 


\subsection{SEAL POT INTERLOCK/ALARM CHECK}

5.11.1 ENSURE Seal Pot Drain Valve VTP-V-160 is in the CLOSED position.

5.11.2 ENSURE Seal Pot Overflow Drain Line Outlet Valve VTP-V-161 is in the FULL OPEN position.

5.11.3 REMOVE Seal Pot fill cap at VTP-V-159.

5.11.4 OPEN Seal Pot fill inlet valve VTP-V-159.

5.11.5 Add water to Seal Pot reservoir UNTIL the seal pot reservoir is $50 \pm 5 \%$ ful1.

5.11.6 RECORD the Seal Pot Level from the Wilkerson Indicator VTP-LI-185. READING:

5.11.7 ENSURE Fan/0ff/Enable Control Selector Switch VTP-HS-103 (Tocated on door of Exhauster Control Cabinet VTP-CP-105) is in the Enable position.

5.11.8 PRESS Fan Start Button VTP-PB-101 (located on door of Exhauster Control Cabinet VTP-CP-105).

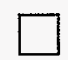

5.11.9 WAIT for the Exhauster fan to come up to speed.

5.11.10 ADD water to the Seal Pot UNTIL the rotating beacon is ILLUMINATED, OR UNTIL a seal pot level of $65 \%$ is indicated on LI105. 


\section{TANK FARIM ACCEPTANCE TEST PROCEDURE}

\subsection{SEAL POT INTERLOCK/ALARM CHECK (Cont inued)}

5.11.11 VERIFY that the Seal Pot Level Wilkerson Indicator VTP-LI-185 is INDICATING a liquid level corresponding to $65 \%$ FULL.

5.11.12 VERIFY the following:

- Message View Display VTP-MV-101 and VTP-MV-102 (10cated at Alarm Cabinet Swing Out Pane1) DISPLAYS "SEAL POT LEVEL HI"

- The exhaust Fan VTP-EF-001 has shutdown.

- $\quad$ Red fan running light is NOT ILLUMINATED.

- Green fan off light is ILLUMINATED.

- Clear Rotating Beacon VTP-XA-101 is ILLUMINATED.

5.11.13 ACKNOWLEDGE the alarm by PRESSING the "1" button, then PRESSING. the "s" button on the Message View Display VTP-MV-101 (located at Alarm Cabinet VTP-ENCL-107 Swing Out Panel) three times. For any secondary alarms repeat this step until all alarms are cleared.

5.11.14 VERIFY Clear Rotating Beacon VTP-XA-101 is NOT ILLUMINATED.

5.11.15 OPEN the Seal Pot drain valve VTP-V-160.

5.11.16 SLOWLY DRAIN the Seal Pot until the alarm message clears.

5.11.17 CLOSE the Seal Pot drain valve VTP-V-160. 


\subsection{SEAL POT INTERLOCK/ALARM CHECK (Cont inued)}

5.11.18 VERIFY Message View Display VTP-MV-102 (1ocated at A1arm Cabinet Swing Out Pane1) CLEARS alarm message at an approximate liquid level that is LESS THAN 60\% FULL, as indicated by the SEAL POT LEVEL WiTkerson indicator VTP-LI-185.

5.11.19 PRESS Fan Start Button VTP-PB-101 (located on door of Exhauster Control Cabinet VTP-CP-105).

5.11.20 WAIT for the Exhauster fan to come up to speed.

5.11.21 CONTINUALLY DRAIN the Seal Pot until rotating beacon ILLUMINATES again, QUICKLY CLOSE the Seal Pot drain valve VTP-V-160.

5.11.22 VERIFY the following:

- Clear rotating beacon VTP-XA-101 is ILLUMINATED.

- Red fan running light is NOT ILLUMINATED.

- Green fan off light is ILLUMINATED.

- Exhauster fan VTP-EF-001 has shutdown.

5.11.23 RECORD the Seal Pot Level indicated by Wilkerson Indicator VTP-LI185 .

READING:

5.11.24 VERIFY the Seal Pot Level Wilkerson Indicator VTP-LI-185 INDICATES a liquid level of $30 \pm 5 \%$ FULL. 


\subsection{SEAL POT INTERLOCK/ALARM CHECK (Continued)}

5.11.25 VERIFY that the Message View Display VTP-MV-101 and VTP-MV-102 DISPLAYS "SEAL POT LEVEL LO".

5.11.26 ACKNOWLEDGE the alarm by PRESSING the "1" button, then pressing the "+" button on the Message View Display VTP-MV-101 (located at Alarm Cabinet VTP-ENCL-107 Swing Out Panel) three times. For any secondary alarms repeat this step until all alarms are cleared.

5.11.27 VERIFY Clear Rotating Beacon VTP-XA-101 is NOT ILLUMINATED.

5.11.28 VERIFY Message View Display VTP-MV-102 (Tocated at Alarm Cabinet Swing out Panel) STILL DISPLAYS "SEAL POT L0".

5.11.29 ADD water to the seal pot reservoir UNTIL the reservoir is $50 \pm 5 \%$ FULL.

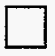




\subsection{GLYCOL INTERLOCK/ALARM CHECK}

5.12.1 ENSURE G1ycol Reservoir Tank VTP-TK-001 drain valve VTP-V-204 is closed.

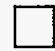

5.12.2 ENSURE Glycol Heater Piping isolation valves are open.

\begin{tabular}{|c|c|c|c|}
\hline Varve number: & (open & hat ve number: & 9pen \\
\hline 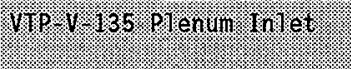 & & 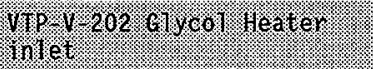 & \\
\hline 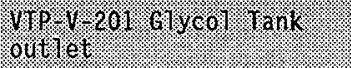 & & & \\
\hline
\end{tabular}

5.12.3 POSITION Circuit Breaker \#3 (1ocated at MPZ Cabinet) to OFF.

5.12.4 DISCONNECT probe leads from transmitter VTP-LT-205.

5.12.5 CONNECT Drexelbrook C-Box to transmitter probe side of transmitter VTP-LT-205.

5.12.6 CONNECT 3-terminal wire to capacitance unit.

5.12.7 SET range switch to NORMAL.

5.12.8 CONNECT Drexelbrook C-Box meter leads in series with VTP-LT-205 OUTPUT.

$\square$

5.12.9 CONNECT terminal wire to meter.

5.12.10 SET meter range to 4-20 mA. 


\subsection{GLYCOL INTERLOCK/ALARM CHECK (Continued)}

5.12.11 PRESS meter ONLY button ON (down).

5.12.12 POSITION Circuit Breaker \#3 (10cated at MPZ Cabinet) to ON.

5.12.13 SET Vernier Dial to 14.5 Picofarads (pf). This is equivalent to 4 $\mathrm{mA}$.

5.12.14 INCREASE Vernier Dial to $60 \mathrm{pf}$. This is equal to approximately $60 \%$ volume $(13.6 \mathrm{~mA})$.

5.12.15 ENSURE circuit breaker \#6 (SLC Control Circuit, Module 8 / VFD001 ) is ON (located in the MPZ cabinet VTP-DP-101).

5.12.16 POSITION Glycol Circulation Pump Control Switch VTP-HS-102 to ON (10cated on door of Exhauster Control Cabinet VTP-CP-105).

5.12.17 VERIFY/RECORD the following:

- Glycol Level Wilkerson Indicator VTP-LI-205 displays a readout corresponding to a $60 \% 1$ evel.

READING:

Glycol Circulation Pump is OPERATING by LISTENING to and/or FEELING the pump.

Glycol System has no leaks.

5.12.18 POSITION Glycol Pump Control Switch VTP-HS-102 to OFF (1ocated on door of Exhauster Control Cabinet VTP-CP-105). 


\subsection{GLYCOL INTERLOCK/ALARM CHECK (Continued)}

5.12.19 ACKNOWLEDGE the PUMP OFF alarm by PRESSING the " 1 " button, then PRESSING the "w" button on the Message View Display VTP-MV-101 (located at A7arm Cabinet VTP-ENCL-107 Swing Out Panel) three times. For any secondary alarms repeat this step until all alarms are cleared.

5.12.19.1 POSITION the GIycol Heater Disconnect Switch VTP-DS-10.2 to OFF

5.12.20 REMOVE the thermostat cover on top of G1ycol Heater VTP-HTR-001.

5.12.21 ENSURE the Heater Thermostat is set to $190^{\circ} \mathrm{F}$.

5.12.22 REPLACE the thermostat cover of G7ycol Heater VTP-HTR-001.

5.12.23 POSITION the G1ycol Heater Disconnect Switch VTP-DS-201 to ON.

5.12.24 POSITION G1ycol Circulation Pump Control Switch VTP-HS-102 to 0N (located on door of Exhauster Control Cabinet VTP-CP-105). 


\subsection{GLYCOL INTERLOCK/ALARM CHECK (Continued)}

\section{WARNING}

Energized circuits and lead are contained inside the cabinet. Observe Appropriate electrical precautions. Comply with HNF-PRO88, ELECTRICAL WORK SAFETY.

5.12.25 VERIFY the GTycol Heater has STARTED by USING the DMM at the Glycol Heater Contactor VTP-CON-206 (10cated at Heat Trace Cabinet VTP-ENCL-104) and PERFORMING the following:

5.12.25.1 RECORD voltage between Terminal T1 and Terminal T2.

READING:

5.12.25.2 VERIFY there is a voltage between Terminal $T I$ and Terminal T2.

5.12.25.3 RECORD voltage between Terminal $\mathrm{T} 1$ and Terminal T3. READING :

5.12.25.4 VERIFY there is a voltage between Terminal T1 and Terminal T3.

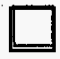

5.12.25.5 RECORD voltage between Terminal $T 2$ and Terminal $T 3$.

READING :

5.12.25.6 VERIFY there is a voltage between Terminal T2 and Terminal T3.

5.12.26 REDUCE the impedance to simulate $50 \%$ Volume $52 \mathrm{pf}(12 \mathrm{~mA})$ on the Glycol Liquid Level Transmitter VTP-LT-205.

5.12.27 VERIFY the following:

- Clear rotating beacon VTP-XA-101 is ILLUMINATED. 


\subsection{GLYCOL INTERLOCK/ALARM CHECK (Continued)}

- Glycol Heater has SHUTDOWN by OBSERVING that the Glycol Heater Contactor VTP-CON-206 (located at Control Cabinet VTP-CP-105) is OPEN.

- GTycol Circulation Pump VTP-P-001 has SHUTDOWN by LISTENING to and/or FEELING the pump.

- Message Disp1ay VTP-MV-101 and VTP-MV-102 DISPLAYS "GLYCOL LEVEL LO".

5.12.28 RECORD the liquid level indication on the Wilkerson liquid level indicator VTP-LI-205.

READING:

5.12.29 ACKNOWLEDGE the alarm by PRESSING the " 1 " button, then PRESSING the "N" button on the Message View Display VTP-MV-101 (located at Alarm Cabinet VTP-ENCL-107 Swing Out Pane1) three times. For any secondary alarms repeat this step until all alarms are cleared.

5.12.30 VERIFY Clear Rotating Beacon VTP-XA-101 is NOT ILLUMINATED.

5.12.31 VERIfY Message View Display VTP-MV-101 (7ocated at Alarm Cabinet Swing Out Pane1) CLEARS alarm message.

5.12.32 POSITION Circuit Breaker \#3 (located at MPZ Cabinet) to OFF.

5.12.33 DISCONNECT the DrexelBrook Calibrator from the Glycol Liquid Leve? Transmitter VTP-LT-205.

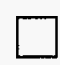

5.12.34 RECONNECT probe leads to transmitter VTP-LT-205. 


\subsection{GLYCOL INTERLOCK/ALARM CHECK (Continued)}

5.12.35 Test Director SHALL VERIFY that section 5.12 is COMPLETE by SIGNING below.

$\overline{\text { Test Director Signature }}$

Date 


\subsection{GLYCOL SYSTEM LEAK CHECK}

This test verifies that the glycol heater, reservoir, and associated piping do not leak to the environment. A visual leak check will be performed followed by a pressure decay test. The following cautions apply to this test section:

\section{CAUTION}

- The system under test shall be pressurized by means of a manifold consisting of a pressure gauge, pressure relief valve, isolation valve, pressure source, and a pressure release valve.

- All system components shall have pressure ratings equal to or greater than the system test pressure.

- The test gauge shall have a dial graduated from zero over a range that in no case shall be less than $1-1 / 2$ or more than four times the intended maximum pressure.

- The pressure relief valve shal1. be set to operate at a pressure that does not exceed $110 \%$ of the test pressure. The relief valve pressure setting shall be verified by use of a calibrated test instrument.

- The flow capacity of the pressure relief valve shall not be less than $125 \%$ of the flow capacity of the pressurizing device.

- A means for immediately shutting off and releasing the pressure shall be provided to prevent damage if the relief valve or other critical system components fail to operate in case of overpressurization.

- All test equipment shal1 be maintained in good operating condition and be capable of withstanding test pressures.

- The Material Safety Data Sheet for Glycol should be reviewed prior to working with that chemical. 


\section{TANK FARM AOCEPTANCE IEST PROGEDURE}

\subsection{GLYCOL SYSTEM LEAK CHECK (Continued)}

5.13.1 OPEN Glycol Heater Piping isolation valves.

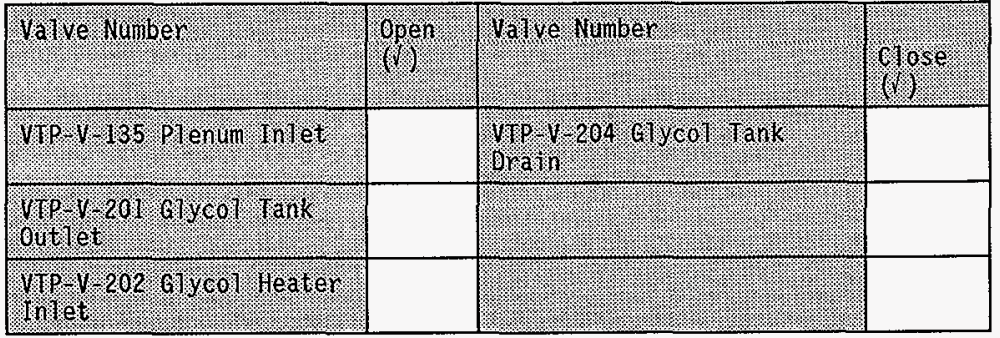

5.13.2 REMOVE the fill cap from the heater reservoir.

5.13.3 CONNECT the pressure supply manifold to the reservoir fill port.

5.13.4 SLOHLY PRESSURIZE the heater reservoir and piping to $10 \mathrm{psig.}$

5.13.5 VISUALLY INSPECT for leaks indicated by Tocalized wetting. Perform this step for a minimum of 15 minutes.

5.13.6 REPAIR any leaks per Test Director direction.

5.13.7 ENSURE the heater reservoir and piping are pressurized to $10 \pm 2$ psig.

5.13.8 ISOLATE the pressure source by closing the manifold isolation valve. 


\subsection{GLYCOL SYSTEM LEAK CHECK (Continued)}

5.13.9 RECORD the initial pressure and time. PRESSURE (psig) TIME

INITIAL:

FINAL:

5.13.10 WAIT 10 minutes.

5.13.11 RECORD the final pressure and time.

5.13.12 VERIFY there was no pressure drop during the 10 minute time period.

Quality Control Signature

\section{Date}

5.13.13 RELIEVE pressure from the system by siowly opening the manifold release valve.

5.13.14 DISCONNECT and REMOVE the pressure supply and manifold.

5.13.15 Test Director SHALL VERIFY that section 5.13 is COMPLETE by SIGNING below.

Test Director Signature

$\overline{\text { Date }}$

5.13.16 QC Inspector SHALL VERIFY that section 5.13 is COMPLETE by SIGNING below.

QC Inspector Signature

Date 


\section{TANK FARIV ACCEPTANCE TEST PROCEDURE}

\subsection{THERMOCOUPLE INTERLOCK/ALARM CHECK}

5.14.1 REMOVE thermocouple TE-179 from the thermowe11.

5.14.2 POSITION the Glycol Heater Disconnect Switch VTP-DS-201 to ON.

5.14.3 ENSURE circuit breaker \#6 (SLC Control Circuit, Module 8 / VFD001 ) is ON (located in the MPZ cabinet VTP-DP-101).

5.14.4 POSITION Glycol Circulation Pump Control Switch VTP-HS-102 to ON (1ocated on door of Exhauster Control Cabinet VTP-CP-105).

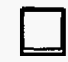

5.14.5 VERIFY GTycol Heater has STARTED by OBSERVING that the GTycol Heater Contactor VTP-CON-206 (located at Control Cabinet VTP-CP105) is CLOSED.

5.14.6 HEAT thermocouple TE-179 with a Hot Air Gun UNTIL the Wilkerson Indicator VTP-TI-179 is indicating $>200^{\circ} \mathrm{F}$.

5.14.7 VERIFY the following:

- Clear Rotating Beacon VTP-XA-101 (located on stack support framing) is ILLUMINATED.

- Message View Display VTP-MV-101 and VTP-MV-102 (located at Alarm Cabinet Swing Out Pane1) DISPLAYS "HEATER AIR TEMP HI".

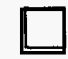

- Glycol Heater has SHUTDOWN by OBSERVING that the GTycol Heater Contactor VTP-CON-206 (located at the Control Cabinet VTP-CP-105) is OPEN. 


\subsection{THERMOCOUPLE INTERLOCK/ALARM CHECK (Continued)}

5.14.8 ACKNOWLEDGE the al arm by PRESSING the "1" button, then PRESSING the "w" button on the Message View Display VTP-MV-101 (located at Alarm Cabinet VTP-ENCL-107 Swing Out Panel) three times. For any secondary alarms repeat this step until all alarms are cleared.

5.14.9 VERIFY Clear Rotating Beacon VTP-XA-101 is NOT ILLUMINATED.

5.14.10 VERIFY Message View Display VTP-MV-101 (1ocated at A1arm Cabinet Swing Out Pane1) CLEARS alarm message.

5.14.11 ALLOW thermocouple TE-179 to cool to $<100^{\circ} \mathrm{F}$.

5.14.12 PLACE thermocouple TE-179 in a cup of ice.

5.14.13 VERIFY the following AFTER the thermocouple indicates $\angle 40^{\circ} \mathrm{F}$ on Wilkerson Indicator VTP-TI-179:

- Clear Rotating Beacon VTP-XA-101 (located on stack supporting framing) is ILLUMINATED.

- RECORD indication on Wilkerson indicator TI-179 (located on door of Exhauster Control Cabinet VTP-CP-105) corresponding to VTP-TE-176.

READING:

- Message View Display VTP-MV-101 and VTP-MV-102 (located at Alarm Cabinet Swing Out Pane1) DISPLAYS "HEATER TEMP L0".

5.14.14 ACKNOWLEDGE the a] arm by PRESSING the "1" button, then PRESSING the "s" button on the Message View Display VTP-MV-101 (located at Alarm Cabinet VTP-ENCL-107 Swing Out Panel) three times. For any secondary alarms repeat this step until all alarms are cleared. 


\subsection{THERMOCOUPLE INTERLOCK/ALARM CHECK (Continued)}

5.14.15 VERIFY Clear Rotating Beacon VTP-XA-101 is NOT ILLUMINATED.

5.14.16 VERIFY Message View Display VTP-MV-102 (Tocated at Alarm Cabinet Swing Out Pane1) DISPLAYS alarm message.

5.14.17 POSITION Circuit Breaker \#3 (located at MPZ Cabinet) to OFF.

5.14.18 REPLACE Thermocouple TE-179 into the thermowe11.

5.14.19 Test Director SHALL VERIFY that section 5.14 is COMPLETE by SIGNING below. 


\subsection{GLYCOL HEATER TEST}

5.15.1 VERIFY GIycol Reservoir Tank VTP-TK-001 is approximately $60 \pm 5 \%$ full by observing level sight glass VTP-LG-201.

5.15.2 ENSURE the Glycol Heater Piping isolation valves are OPEN or CLOSED as indicated below:

\begin{tabular}{|c|c|c|c|}
\hline 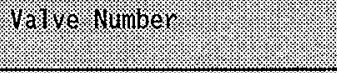 & moer & 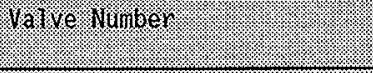 & 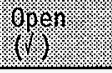 \\
\hline 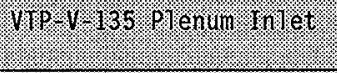 & & 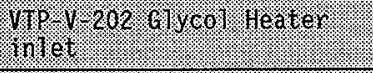 & \\
\hline 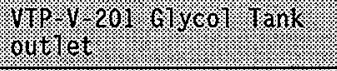 & & 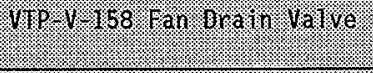 & \\
\hline 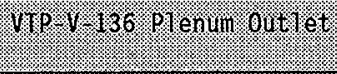 & & & 6rosed \\
\hline & & Mr & \\
\hline
\end{tabular}

5.15.3 POSITION circuit breaker \#6 (7ocated in the MPZ cabinet VTP-DP101) to OFF.

5.15.4 REMOVE the thermostat cover on top of G1ycol Heater VTP-HTR-001.

5.15.5 ENSURE the heater thermostat is set to $190^{\circ} \mathrm{F}$.

5.15.6 REPLACE the thermostat cover on top of G1ycol Heater VTP-HTR-001.

5.15.7 POSITION circuit breaker \#6 (located in the MPZ cabinet VTP-DP101) to $0 \mathrm{~N}$.

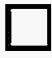

5.15.8 POSITION the EXHAUSTER FAN MOTOR DISCONNECT SWITCH VTP-DS-102 to ON. 


\subsection{GLYCOL HEATER TEST (Continued)}

5.15.9 PRESS Fan Start Button VTP-PB-101 (Located on door of Exhauster Control Cabinet VTP-CP-105) to turn ON Exhauster Fan VTP-EF-001.

5.15.10 POSITION the GTycol Heater Disconnect Switch VTP-DS-201 to ON.

5.15.11 POSITION G7ycol Circulation Pump Control Switch VTP-HS-102 to ON (1ocated on door of Exhauster Control Cabinet VTP-CP-105) and record initial values for time, inlet temperature, and outlet temperature below.

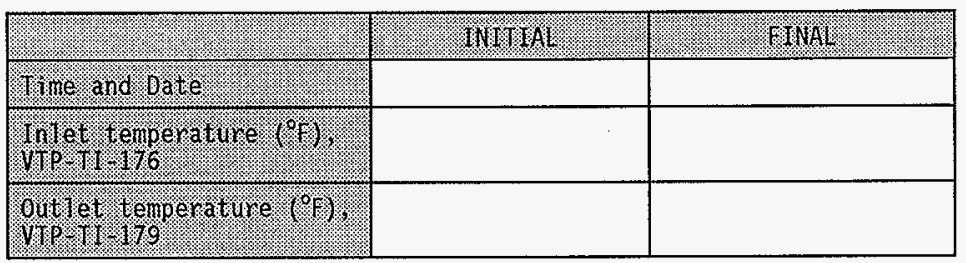

5.15.12 CONTINUE exhauster operation until the airflow temperature indicated by thermocouple VTP-TI-179 has stabilized to vary $\pm 2^{\circ} \mathrm{F}$ or less.

5.15.13 RECORD final values for time, inlet temperature, and outlet temperature.

5.15.14 VERIFY the final outlet temperature is AT LEAST $20^{\circ} \mathrm{F}$ greater then the final inlet temperature.

5.15.15 POSITION the Glycol Heater Disconnect Switch VTP-DS-201 to OFF.

5.15.16 POSITION G1ycol Circulation Pump Control Switch VTP-HS-102 to off (located on door of Exhauster Control Cabinet VTP-CM-105). 


\subsection{GLYCOL HEATER TEST (Continued)}

5.15.17 POSITION the EXHAUSTER FAN MOTOR DISCONNECT SWITCH VTP-DS-102 to OFF.

5.15.18 Test Director SHALL VERIFY that section 5.15 is COMPLETE by SIGNING below.

$\overline{\text { Test Director Signature }}$

$\overline{\text { Date }}$


DATA SHEET 1 - LEAKAGE RATE CALCULATION (This page may be reproduced as necessary) DATE: TEST \#:

\begin{tabular}{|c|c|c|}
\hline & INITIAL & FINAL \\
\hline Time & $t i=$ & $t f=$ \\
\hline Pressure (psig) & $\begin{aligned} P i & =\longrightarrow \text { IN W.C./ } 27.7 \\
& =\end{aligned}$ & $\begin{aligned} \text { Pf } & =\longrightarrow \text { IN W.C. / } 27.7 \\
& =\end{aligned}$ \\
\hline Barometric pr ( IN Hg) & $\begin{aligned} \mathrm{BPi} & =\ldots \ldots \text { IN Hg } \times 0.491 \\
& =\end{aligned}$ & $\begin{aligned} \text { BPf } & =\_ \text {IN Hg } \times 0.491 \\
& =\end{aligned}$ \\
\hline Duct pr (psfa) & $\begin{aligned} D P i & =(P i+B p i)(144) \\
& =\end{aligned}$ & $\begin{aligned} D P f & =(P f+B p f)(144) \\
& =\end{aligned}$ \\
\hline Temperature $\left({ }^{\circ} R\right)$ & $\begin{aligned} T i & =\longleftarrow \\
& =\end{aligned}$ & $\begin{aligned} T f & ={ }^{\circ} \mathrm{F}+460 \\
& =\end{aligned}$ \\
\hline
\end{tabular}

Test Volume: $\quad \mathrm{V}=$ cubic feet

Gas constant: $\quad R=53.35 \mathrm{ft} 1 \mathrm{~b} /\left(1 b^{*} \operatorname{deg} R\right)$

Test Duration: $\quad \Delta t=(t f-t i)=$ minutes

$Q=(\mathrm{DPi} / \mathrm{Ti}-\mathrm{DPf} / \mathrm{Tf}) \mathrm{V} /(\mathrm{R} \times \Delta \mathrm{t} \times 0.075)=$ SCFM

$Q$ is the Average total leak rate per ASME N510-1989, Section 6.5.3.9, in standard $\mathrm{ft}^{3} / \mathrm{min}$ (SCFM).

$L_{s}=$ Allowable Leak Rate $=0.3$ SCFM

$\overline{\text { Test Director Signature }} \overline{\text { Date }} \overline{\text { QC Signature }} \overline{\text { Date }}$

$\overline{\text { Checker Signature }} \overline{\text { Date }}$ 
DATA SHEET 2 - LEAKAGE RATE CALCULATION (This page may be reproduced as necessary) DATE:

\section{TEST \#:}

\begin{tabular}{|c|c|c|}
\hline & INITIAL & FINAL \\
\hline Time & $t i=$ & $t f=$ \\
\hline Pressure (psig) & $\begin{aligned} \mathrm{Pi} & =\ldots \text { IN W.C./ } 27.7 \\
& =\end{aligned}$ & $\begin{aligned} \text { Pf } & =— \text { IN W.C. / } 27.7 \\
& =\end{aligned}$ \\
\hline Barometric pr (IN Hg) & $\begin{aligned} \mathrm{BPi} & =\ldots \mathrm{IN} \mathrm{Hg} \times 0.491 \\
& =\end{aligned}$ & $\begin{aligned} \mathrm{BPf} & =\longleftarrow \text { IN Hg } \times 0.491 . \\
& =\end{aligned}$ \\
\hline Duct pr (psfa) & $\begin{aligned} D P i & =(P i+B p i)(144) \\
& =\end{aligned}$ & $\begin{aligned} D P f & =(P f+B p f)(144) \\
& =\end{aligned}$ \\
\hline Temperature $\left({ }^{\circ} R\right)$ & $\begin{aligned} T i & =\longleftarrow \\
& =\end{aligned}$ & $\begin{aligned} T f & ={ }^{\circ} \mathrm{F}+460 \\
& =\end{aligned}$ \\
\hline
\end{tabular}

Test Volume:

$\mathrm{V}=$

cubic feet

Gas constant: $\quad R=53.35 \mathrm{ft} 1 \mathrm{~b} /(1 \mathrm{~b} *$ degR $)$

Test Duration: $\quad \Delta t=(t f-t i)=$ minutes

$Q=(D P i / T i-D P f / T f) V /(R \times \Delta t \times 0.075)=$ SCFM

$Q$ is the Average total leak rate per ASME N510-1989, Section 6.5.3.9, in standard $\mathrm{ft}^{3} / \mathrm{min}$ (SCFM).

$L_{s}=$ Allowable Leak Rate $=0.3 \mathrm{SCFM}$

$\overline{\text { Test Director Signature }} \overline{\text { Date }} \overline{\text { QC Signature }} \overline{\text { Date }}$

Checker Signature

Date 


\section{ATP EXCEPTION LOG}

This page may be reproduced as necessary PAGE of

\begin{tabular}{|c|c|c|}
\hline \multicolumn{3}{|c|}{ ATP EXCEPTION LOG } \\
\hline Number & Date & Description \\
\hline & & \\
\hline & & \\
\hline & & \\
\hline & & \\
\hline & & \\
\hline & & \\
\hline & & \\
\hline & & \\
\hline & & \\
\hline & & \\
\hline & & \\
\hline & & \\
\hline & & \\
\hline & & \\
\hline & & \\
\hline & & \\
\hline & & \\
\hline
\end{tabular}




\section{TANK FARM ACCEPTANCE TEST PROCEDURE}

\section{ATP EXCEPTION RECORD}

This page may be reproduced as necessary.

\begin{tabular}{||l|l|}
\hline ATP step number: & ATP Exception Log Number: \\
\hline \hline Description of Exception: & \\
\hline & \\
\hline & \\
\hline Resolution of Exception: & \\
\hline & \\
\hline & \\
\hline & \\
\hline Date of Resolution: & \\
\hline Test Director signature: & \\
\hline Cognizant Engineer signature: & \\
\hline
\end{tabular}

